NASA Technical Memorandum 104444 AIAA-91-2326

\title{
Ground Testing on the Nonvented Fill Method of Orbital Propellant Transfer: Results of Initial Test Series
}

David J. Chato

Lewis Research Center

Cleveland, Ohio

Prepared for the

27th Joint Propulsion Conference

cosponsored by the AIAA, SAE, ASME, and ASEE

Sacramento, California, June 24-27, 1991 


\author{
GROUND TESTING OF THE NONVENTED FILL METHOD OF ORBITAL \\ PROPELLANT TRANSFER: RESULTS OF INITIAL TEST SERIES \\ David J. Chato \\ National Aeronautics and Space Administration \\ Lewis Research Center \\ Cleveland, Ohio 44135
}

\begin{abstract}
This paper presents the results of a series of no-vent fill experiments conducted on a $175 \mathrm{ft}^{3}$ flightweight hydrogen tank from December, 1989 to February, 1990. The experiments consisted of the nonvented fill of the tankage with liquid hydrogen using two different inlet systems (top spray, and bottom spray) at different tank initial conditions and inflow rates. Nine tests were completed of which six filled in excess of $94 \%$. The experiments demonstrated a consistent and repeatable ability to fill the tank in excess of 94 percent using the nonvented fill technique. Ninety-four percent was established as the high level cutoff due to requirements for some tank ullage to prevent rapid tank pressure rise which occurs in a tank filled entirely with liquid. The best fill was terminated at 94 percent full with a tank internal pressure less than 26 psia. Although the baseline initial tank wall temperature criteria was that all portions of the tank wall be less than $40 \mathrm{R}$, fills were achieved with initial wall temperatures as high as $227 \mathrm{R}$.
\end{abstract}


On orbit transfer of cryogenic liquids is considered enabling to many future NASA missions, from space transfer vehicles (STV) to manned mars exploration. The techniques required to transfer cryogens in low gravity are quite different from those used terrestrially. During a normal-gravity fill, a top vent is kept open to vent the vapor generated during the fill process thereby maintaining a low tank pressure. If the normal-gravity technique is used onorbit, the uncertainty of liquid and vapor distributions in low gravity may result in the dumping of large amounts of liquid overboard. The no-vent fill process is a methodology used to reduce fluid loss by allowing the tank vent to be kept closed while the tank is filling (ref. 1).

The procedure works as follows: The tank wall is cooled to a temperature sufficient to remove most of its thermal energy. Sprays and/or jets are used to inject the incoming liquid into the storage tank with the vent closed, thereby mixing the tank contents and promoting heat transfer between the liquid and vapor phases. Excessive vapor generation and compression is avoided. This allows the liquid transfer to proceed at moderate pressures to a very high level of liquid fill with the vent closed.

Concepts for missions involving orbital fluid transfer can be found as early as the planning stages of the Apollo Program (ref. 2). One of the earliest detailed designs of an orbital fluid transfer system is found in reference 3. The reference 3 study proposed designs for $\mathrm{LO}_{2}$ and $\mathrm{LH}_{2}$ tankers based on an equilibrium analysis of the thermodynamics of the fill process, including vented and nonvented transfer methods. Reference 4 demonstrated one-g nonvented fills experimentally with $\mathrm{LN}_{2}$ and $\mathrm{LF}_{2}$ in conjunction with liquid fluorine loading studies. After an extensive survey of the existing literature, reference 5 formulated a transfer system for support of a shuttlebased space tug using a low-g settling vented transfer. This system, however, required either long transfer times or lange quantities of settling thrust propellant. Follow-on studies (refs. 6 and 7) devised nonvented transfer schemes for the space tug and its successor, the orbital transfer vehicle (OTV), including transient analyses of the nonvented fill process. These analyses reconfirmed the difficulty of $\mathrm{IH}_{2}$ transfer described in the previous equilibrium analyses. As a solution to the problem of nonvented hydrogen transfer, a chilldown procedure was proposed to reduce the thermal energy which must be absorbed in the nonvented fill process. The NASA Lewis Research Center (LeRC) Cryogenic Fluid Technology office (CFTO) has refined and extended the analyses of references 6 and 7 (see refs. 1 and 8), as well as conducting ground testing of the nonvented fill concept. Small-scale testing (ref. 9) is leading to refinement and validation of the analyses. To determine the feasibility of nonvented fills on tanks more representative of space flight hardware, a series of liquid hydrogen no-vent fill tests were developed for an existing $175 \mathrm{ft}^{3}$ lightweight liquid hydrogen tank (ref. 10). This paper presents the results of those tests. 


\section{FACILTTIES}

The tests were conducted at the LeRC Plum Brook Station Cryogenic Propellant Tank Facility (also known as K-Site). This facility combines a capability for safely handling liquid hydrogen with the vacuum required for multilayer insulation systems. The facility has a $25^{\prime}$ diameter spherical vacuum chamber with a 20' diameter entry door (fig. 1 shows the chamber with hardware from a previous test). Figure 2 is a simplified system schematic of the test facility as configured for the current test series. Extensive provisions have been made for the safe use of hazardous cryogens in the test facility. These provisions include two $\mathrm{H}_{2}$ burnoffs for venting, a remotely located control room (the control room and burnoff locations are shown on the aerial view of the facility in figure 3), a catch basin (seen at the bottom of figure 2) to contain the cryogen in the event of catastrophic failure of the test article in the chamber, and a burn pit to drain the catch basin of cryogens and flare it off. The chamber is rated for an $8 \times 10^{-7}$ torr vacuum under clean, dry, and empty conditions. The vacuum was maintained between $10^{-6}$ torr and $10^{-5}$ torr during the tests. A mass spectrometer provided continuous monitoring of residual gas in the chamber and was extremely useful in detecting leakage.

A cryoshroud was installed inside the chamber (figure 4) to provide a uniform heat transfer environment. This shroud is cylindrical and $13^{\prime}$ in diameter by 13' long. During the tests it was filled with 30 psia saturated liquid nitrogen to provide a uniform $160 \mathrm{R} \pm 10 \mathrm{R}$ radiant environment for the test tank. The shroud was draped in aluminized mylar to reduce the radiant heat transfer to the cryoshroud from the chamber walls. Mounted on the cryoshroud was a $2^{\prime} \times 5^{\prime}$ cylindrical coldguard (also in figure 4). During testing, the coldguard is filled with liquid hydrogen boiling at near atmospheric conditions. All test tank lines, except the bypass line, pass through the coldguard and all instrumentation leads are thermally shorted to the coldguard. The coldguard minimizes the heat load to the test tank by absorbing the conduction heat transfer from the ambient enviromment along the test tank lines and instrumentation wires.

Liquid hydrogen for testing was supplied by a 13,000 gallon roadable dewar located outside the facility building. Prior to testing, the dewar was vented to nearly atmospheric pressure (roughly $1.6 \mathrm{psig)}$ and maintained there to cool the hydrogen to a uniform low saturation temperature throughout the dewar. During the test, the tank was pressurized to the desired transfer head by withdrawing a controlled quantity of liquid hydrogen, feeding it through a vaporization coil located under the dewar, and forcing the resultant gas back into the dewar. Due to the thermal lag between the raising of the tank pressure and the time for the cooled bulk liquid temperature to rise to the corresponding saturation temperature, a quantity of subcooled liquid hydrogen was available for transfer.

The subcooled liquid hydrogen supply from the dewar flowed through a short section of vacuum jacketed flex hose into a vacuum insulated pipe which carried the liquid hydrogen through the coldguard to the test tank valving.

Foam insulated pipe carried vent gases from the test tank out to the burnoffs for disposal. A new vent system was installed which enabled the test tank to 
be pulled down to hydrogen triple point pressures prior to the start of a test. This was accomplished by a $950 \mathrm{cfm}$ vacuum pump. The flow was warmed to ambient temperature by a $30 \mathrm{kw}$ electric heater prior to reaching the pump. oxygen levels in the vacurm pump discharge were monitored to guard against air leakage. As an additional precaution all pipe joints in the line outside the chamber were purged with helium.

\section{EXPERTMENTAL HARDWARE}

\section{Test Tank}

The test tank selected was the liquid hydrogen tank designed and built for use in the Research Propulsion Module (RPM) program conducted by Lewis Research Center in the early seventies (ref. 11). The RPM liquid hydrogen tank is ellipsoidal with a 87 inch major diameter and a 1.2-to-1 major-to-minor axis ratio. The two ends are joined by a short 1.5 inch cylindrical section. The tank is made of 2219 aluminum chemically milled to a nominal thickness of 0.087 inches. Thicker sections exist where they were required for manufacturing (mainly weld lands). The tank has a 28.35 inch access flange on the top. The tank weighs 329.25 pounds, and the tank's volume is $175 \mathrm{ft}^{3}$. The tank was originally designed for a maximum operating pressure of 80 psia. Prior to the start of testing the tank was requalified by pneumatic test for a maximum operating pressure of $50 \mathrm{psia}$. The tank is covered with a blanket of 34 layers of multi-layer insulation (MII) made with double aluminized mylar and silk net spacers, and is supported by 12 fiberglass epoxy struts. The thermal performance of the tank is documented in reference 11. Figure 5 shows the tank installed in its support structure suspended over the cryoshroud. This tank has several features which make it desirable as a test bed for development of spacecraft technology. First, it is of the same lightweight chemically milled construction used in space flight tanks. Second, it has a MII blanket with performance nearly identical to current insulation designs for STV. Finally, the tank is similar in size and shape to much of the tankage proposed for flight experimentation. Ground-based testing with the tank will allow the CFTO to assess similar problems to those encountered in space.

\section{Spray Systems}

Current concepts (refs. 1, 6 and 8) of space no-vent fill systems use one or more pressure atomizing spray nozzles to inject the liquid inflow as a stream of droplets through the ullage, thereby promoting condensation of the ullage gas on the droplet stream. As the tank fills, these nozzles will submerge and it is expected that the outflow will transform to a liquid jet within the bulk tank liquid. This jet will continue to promote condensation by using fluid mixing to transport colder liquid to the liquid free-surface. It is expected that the droplet spray will produce much higher condensation rates than the submerged jet since a larger surface area is available for heat transfer.

Unfortunately, for the spacecraft designer, the location of the ullage bubble in zero-gravity is uncertain. Therefore, prediction of the conditions under which the spray nozzles will submerge is difficult. In order to bound the problem, two spray systems were selected. One spray system has a single spray 
nozzle at the bottom of the tank. This represents the worst case since it will flood soon after liquid begins to accumulate in the tank (at approximately $7 \%$ liquid). The other spray system uses a cluster of 13 spray nozzles spraying from the top of the tank (13 spray nozzles were selected due to the availability of a commercial spray manifold with this configuration). These nozzles are located in a position such that the spray nozzles are not submerged until the tank is $92 \%$ full of liquid hydrogen.

The flow capacities of each system are sized, within the constraints of commercially available nozzle sizes, to have the same inflow rate for the same inlet pressure. Details of the nozzle sizing can be found in reference 10. The nozzles were sized to provide roughly $10001 \mathrm{bm} / \mathrm{hr}$ hydrogen at a pressure drop of $10 \mathrm{psi}$ (from the analysis of reference 10 this should correspond to $7.34 \mathrm{gpm}$ of water at the same pressure drop). For the bottom spray a commercial full cone nozzle with a flow capacity of $8.3 \mathrm{gpm}$ water at $10 \mathrm{psi}$ was selected (ref. 12). This nozzle has a nominal orifice diameter of 0.375 inches and a $C_{0}$ of approximately 0.6 . For the top spray, a manifold of 13 full cone nozzles each with a flow capacity of $0.50 \mathrm{gpm}$ water at $10 \mathrm{psi}$ giving a total flow of $6.5 \mathrm{gpm}$ water were selected (ref. 12). These have a nominal orifice diameter of 0.082 inches and $a C_{D}$ of approximately 0.8 . Figure 6 shows the two spray systems selected.

Figure 7 shows the spray systems suspended from the tank lid. Also visible are the test tank instrument rake and capacitance level sensor. Figure 8 illustrates the installed position of these systems in the tank. Because there are only four ports available in the current tank lid for feedthroughs, the spray systems were brought through one port via the concentric tube arrangement illustrated in figure 9. Port assignments are spray systems, capacitance probe, vent/pressurization line, and instrumentation electrical connector.

\section{Test Tank Valving}

A schematic of the tank valving and instrumentation inside the chamber is shown in Figure 10. Valving from the RPM tank test is used for controlling the fill-drain line (Valves 2513, and 2514) and the tank vent (valve 2515). Valve 2501 is teed into the fill-drain line between the coldguard and valve 2513. Valve 2501 controls flow to the spray systems. At the top of the tank, the line from 2501 splits into three lines. Two of these lines provide flow to the bottom and top spray, and each is controlled by its own valve (2502 for the top spray, 2503 for the bottom jet). The third line bypasses flow out the facility vent. The bypass is used to cool the lines prior to the start of tests. Flow through the bypass is controlled by a valve outside the chamber.

\section{INSTRUMENTATION}

Instrumentation for lines external to the test tank are shown on the figure 10 schematic. Instrumentation internal to the tank and on the tank wall is shown in figures 11 and 12 . 


\section{Flowmeter}

Flow measurements are provided by a bidirectional venturi (preexistent from earlier tests) and two turbine flowmeters. The venturi is located in the inflow line inside the chamber and provides flow measurement for all inlet systems. The venturi was calibrated with water over a range of flow from 1 gpm to $15 \mathrm{gpm}$ (this is estimated to correspond to a range $3.76 \mathrm{gpm}$ to $56.4 \mathrm{gpm}$ of hydrogen). Two 0-1 psi delta pressure transducers provide pressure drop measurements for the bi-directional venturi. Delta pressure transducer accuracy is estimated at $\pm 3 / 4 \%$ full scale. Venturi resolution is limited by the accuracy of the 0-1 psid transducers. Estimated error in venturi reading is \pm 1 gpm water at the lowest flow rate and \pm 0.1 gpm water at the highest flow rate. Turbine flow meters are located at the inlet to each spray system; they provide a more accurate measure of flow than the venturi. The range of the turbine meters is from 0.6 to $60 \mathrm{gpm}$ with an accuracy of $\pm 1 / 2 \%$ of reading.

\section{Pressure}

All pressure transducers are mounted outside the vacuum chamber and connected to the measurment taps by $1 / 4 "$ or $3 / 8 "$ stainless steel tubes. Pressure transducers rated at 0-50 psia are located at the venturi inlet, upstream of the turbine flow meters and downstream of the spray system inlet valves. Installed accuracy is estimated at $\pm 1 / 2 \%$ full scale. A 0-50 and a 0-100 psia transducer measure tank pressure from a tap in the capacitance probe. An oscillation problem, believed to be thermo-acoustic oscillation, limited accuracy on the capacitance tap to \pm 2 psia.

\section{Tank Internal Instrumentation}

Internal instrumentation consists of a capacitance level sensor and a rake of temperature and point level sensors. Stainless steel was selected as the material for internal instrument support due to its low thermal conductivity relative to other metals. The capacitance probe measures liquid fill heights between 2.9 and 66.7 inches from the tank bottom by measuring the change in capacitance of two concentric stainless steel tubes as the annular space between them fills with liquid hydrogen. Changes to the dielectric constant of hydrogen with pressure prevent the accuracy of the probe from being better than $\pm 1 \%$ full scale. The rake for other sensors is supported off the outer tube of the capacitance probe. The main body of the rake is a stainless steel sheet 1/8" thick by 1.5" wide and 63.84" long. Eight hot wire point level sensors are installed on this rake at the locations shown in figure 11. A stainless angle piece below each sensor was installed to deflect bubbles rising from the bulk liquid. Unfortunately these sensors proved incapable of other than gross indication of the liquid level while the fill was proceeding. Seventeen silicon diode temperature sensors are installed on the rake as shown in figure 11. To further thermally isolate these sensors they are mounted on 1" x 1.1" G10 micarta cards. Six of these are clustered on a single larger 2.18 " $x$ 1.1" G10 card near the 85\% fill level to measure thermal stratification. Accuracy of these diodes is $\pm 0.5 \mathrm{R}$ to $45 \mathrm{R}$ and $\pm 0.9 \mathrm{R}$ at higher temperatures. 


\section{External Temperatures}

Silicon diode temperature sensors are used to measure temperature on the plumbing and tank wall: Two such sensors are located just downstream of the turbine flow meters, two are downstream of the spray system inlet valves, four are on the tank wall, four are on the tank fill/drain line, and two are - on the tank lid. These diodes are slightly less accuracy than the internally mounted ones, accuracy is $\pm 0.9 \mathrm{R}$ below $180 \mathrm{R}$ and $1 \%$ of reading above that 180 R. A platinum resistance thermometer(PRT) inserted in a well located near the venturi is used to measure venturi liquid temperature with an accuracy of $\pm 0.2 \mathrm{R}$ over a range of 36 to $70 \mathrm{R}$. Facility systems and tank insulation are instrumented with a variety of PRIs, Type $\mathrm{E}$ and Type $\mathrm{K}$ thermocouples selected for predicted temperature and required accuracy.

\section{Data collection}

Data is collected by the NASA LeRC ESCORT-D (see ref. 13 for more detail) mini-computer based system. Analog inputs from the facility are converted by a 12 bit analog-to-digital converter and updated once a second. ESCORT software converts the digital signal to engineering units and updates user designed displays on five CRT units located in the K-Site control building. Software routines are also used to convert temperature, pressure and volumetric flow readings into mass flow rates. Approximately 412 channels of data are recorded in the current test series. Data is recorded during the novent fill test runs once every 15 seconds for the first 10 minutes followed by once every minute for up to 4 hours. Data recording is started manually just prior to opening the inlet valves to start the test.

\section{TEST OBJECTIVES}

The objectives of the test were to demonstrate the feasibility of the nonvented fill on large flightweight tanks, compare fill systems, and characterize the effect of flow rate and initial wall temperature on the nonvented fill process. Constraints were as follows. The tank was limited by qualification testing to a maximum operating pressure of $50 \mathrm{psia}$. The tank was limited to a maximu fill level of $94 \%$ due to requirements for some tank ullage to prevent the rapid tank pressure rise which occurs in a tank filled entirely with liquid. Due to the design of the transfer system, flow rate was determined by the selection of a the supply dewar pressure. Maximum lid temperature prior to the start of the spray systems was restricted to $250 \mathrm{R}$ to prevent excessive thermal shock to the tank lid when impacted with liquid hydrogen spray. A matrix of tests was formulated using both spray systems, dewar pressures of 30 and 45 psia, and initial wall temperatures of less than $40,140,200$, and $250 \mathrm{R}$ (note not all combinations of parameters were included in the matrix and although the entire matrix was run some tests were discarded due to equipment failure). 
TEST PROCEDURE(Representative)

Initial conditions:

- Vacum $<10^{-5}$ Torr
- $\quad$ Tank filled with $\mathrm{GH}_{2}$
- $\quad$ Cryoshroud filled and operating at $160 \mathrm{R}$
- $\quad$ cold guard filled and maintained at 18 psia pressure

Detailed Procedure:

1. Fill or top-off the tank (if partially full from previous test) to insure that tank lid and flange are at or below desired initial temperature (SD31, SD32)

2. Empty the tank by transferring $\mathrm{LH}^{2}$ to external receiver dewar, close all inlet valves, and begin vacuum pumpdown of tank to $<2$ psia.

3. Establish a by-pass flow of sub-coled $\mathrm{LH}_{2}$ with supply dewar pressure maintained at 45 psia.

4. Allow by-pass line to thermally stabilize (temperature SD 28 reads near $40 \mathrm{R})$.

5. With the tank internal pressure at $<2$ psia, close tank vent and terminate vacuum pumping.

6. Initiate a no-vent fill through the spray nozzle by opening the valve for the nozzle inlet and closing the by-pass valve. Maintain a constant supply pressure throughout the test.

7. Terminate the fill when the 94 percent fill level is reached or when the tank pressure reaches 50 psia, whichever occurs first. Depressurize supply dewar and vent it to near atmospheric.

8. Allow the tank to remain unvented and quiescent for one hour following the fill unless pressure exceeds 52 psia; the tank must be vented if the pressure exceeds 52 psia. Record data throughout this period also.

TEST RESULTS

Completed no-vented fill runs are summarized in table 1. A total of nine tests were completed without equipment failure; of these, three were terminated due to lack of transfer head and six were stopped at the maximum 94\% fill level. Detailed pressure and temperature histories are discussed below.

\section{Pressure and Inlet conditions}

Initial tests were conducted with both spray systems. Pressure, fill level, inlet flow rate, and inlet temperature for these tests are shown in Figure 13. Due to the presence of 10 micron filters in the transfer lines, flow rates were limited to a nominal $500 \mathrm{lbm} / \mathrm{hr}$. At this flow rate, it was not possible to maintain a constant subcooling for the liquid flow due to envirommental heat leak to the transfer line. Figure 13 clearly shows an increasing inlet temperature as the fill process progresses. All of these fills were ended at less than $60 \%$ full. 
A brief halt in testing permitted access to the plumbing inside the vacurm chamber and the 10 micron filters were removed from the lines. This permitted the testing of each individual spray system at the $1000 \mathrm{lbm} / \mathrm{hr}$ flow rate necessary to maintain a constant inflow temperature. Figure 14 shows key parameters during top spray fills. All fills exceeded 94\%. Increased initial wall temperature results in higher final fill pressures.

Figure 15 shows key parameters measured during bottom jet testing. Again, final fill pressure was a function of initial wall temperature, although the result is less pronounced for the $120 \mathrm{R}$ wall start. All fills exceed $94 \%$

\section{Temperature Data}

Figures 16 to 24 show wall and internal temperatures for the test runs. Internal temperature sensors failed intermittently throughout the test. This problem is believed to be a thermal expansion problem in the connector through which the sensor wires pass through the tank lid. Failed sensors have been omitted from the figures. Several features are worth extra notice in the temperature data. The bottom jet fills show gas stratification (about 10 degrees for the worst case; fill 18). The top sprays show no gas side stratification. The top spray test shows some liquid stratification particularly on the colder wall temperature tests. This is believed to represent residual liquid from the prechill process which is never mixed with the bulk liquid. Some of the bottom jet data shows this stratification early on but the bottom jet provides sufficient mixing so that the stratification does not persist throughout the fill process.

\section{DISCUSSION}

Several key conclusions can be drawn from examination of the data presented. The primary conclusion is that nonvented fill is a feasible technique for well insulated tanks of this size under normal gravity conditions. Other findings are that both spray systems are capable of filling the tank, and initial wall temperatures as high as $227 \mathrm{R}$ do not preverit the filling of the tank. The lowest pressure fill, test 18, filled at a maximum pressure of 25.6 psia.

Fills with both spray systems achieve the desired liquid fill level of $94 \%$ Since the fill systems were selected as bounding cases for the low gravity fill, the fact that both systems were capable of filling the tank show promise for the feasibility of nonvented fill technique in the desired on-orbit application. Direct comparison between spray systems is difficult due the variation in conditions between the top and bottom sprays. However comparison between tests 18 and 21 (which are the runs where conditions match the closest) indicate a slight advantage for the top spray system (roughly 0.9 psi lower)

High initial wall temperature did increase the final fill pressure, but average wall temperatures as high as $227 \mathrm{R}$ did not prevent filling tanks to 94\% liquid. Test 20, the fill with the $227 \mathrm{R}$ wall temperature is $7 \mathrm{psi}$ higher at maximu fill than test 23 the best top spray. Similarly test 21, the bottom spray fill with the warmest initial wall temperature ends at 8 psi higher than the best bottom spray test (test 18). 
The principle reason for incomplete fills appears to be the inability to maintain inlet temperature during the low flow rate tests(tests 1,2 and 3). A rising inflow temperature resulted in increased liquid saturation pressure and a subsequent increased tank pressure. An increased tank pressure causes the inflow rate to drop. A dropping inflow rate, in turn, leads to a further increase in inflow temperature. In the top spray system, this cycle was particularly severe resulting in a maximu fill of only $53 \%$.

Some anomalous behavior is encountered in the test data. Flow rate does not always decrease with increasing pressure. Tests 1 and 3 show some severe flow rate spikes and all tests show some flow rate spikes during the initial portions of the fill. The most likely cause for this is two phase flow in the transfer line. Some fluctuation of the fill level is seen in tests 18 to 23. This fluctuation is most severe in the bottom spray fill. The level fluctuation is probably attributable to the disturbance of the liquid free surface by the spray. The oscillation of tank pressure reading has been discussed in the pressure instrumentation section result in a worst case error of $+8 \%$ on final fill pressure, which is more than was desired for thermodynamic analysis of the fill process.

Results of the phase IA test indicate several areas for continued work. Test results are currently being compared with the previous analytical work. Plans for follow-on testing are underway. Near term follow-on tests repeat of some of the current test matrix with more stable inlet conditions and improved instrumentation, as well as some new higher flow rate testing. Testing is also planned for different inlet subcooling, different spray systems, and whether in-tank mixers can improve the process.

It is the author's belief that even without the follow-on work, the tests already completed represent a substantial contribution to the study of nonvented transfer. The test results presented in this paper were achieved with hardware which is an order of magnitude larger than that for any previous tests; the results clearly demonstrate repeatable nonvented fills. 


\section{REFERENCES}

1. Chato, D.J., "Thermodynamic Modeling of the No-Vent Fill Methodology for Transferring Cryogen in Low-Gravity," AIAA Paper 88-3403, July 1988 (NASA TM-100932).

2. Bilstein, R.E., "Stages to Saturn," NASA SP-4206, 1980.

3. Morgan, L.L., et al., "Orbital Tanker Design Data Study," Lockheed Missiles and Space Co., LMSC-A748410, 1965.

4. Fester, D.A., Page, G.R., and Bingham, P.E., "Liquid Fluorine No-Vent Loading Studies," AIAA Journal of Spacecraft, Vol. 7, No. 2, 1970.

5. Stark, J.A., "Low-G Fluid Transfer Technology Study," NASA CR-134911, 1976.

6. Merino, F., Risberg, J.A., and Hill, M., "Orbital Refill of Propulsion Vehicle Tankage," NASA CR-159722, 1980.

7. Merino, F., Blatt, M.H., and Thies, N.C., "Filling of Orbital Fluid Management Systems," NASA CR-159404, 1978.

8. DeFelice, D.M. and Aydelott, J.C., "Thermodynamic Analysis and Subscale Modeling of Space-Based Orbit Transfer Vehicle Cryogenic Propellant Resupply," AIAA Paper 87-1764, June 1987 (NASA TM-89921) .

9. Moran, M.E., Nyland, T.W., and Papell, S.S., "Liquid Transfer Cryogenic Test Facility--Initial Hydrogen and Nitrogen No-Vent Fill Data," NASA TM-102572, March 1990.

10. Chato, D.J. "Analysis of the Nonvented Fill of a 4.96 cubic Meter Lightweight Liquid Hydrogen Tank," ASME Paper 89-HT-10, Aurgust 1989 (NASA TM-102039).

11. DeWitt, R. L. and Boyle, R. J., "Thermal Performance of an Integrated Thermal Protection System for Long-Term Storage of Cryogenic Propellants In-Space", NASA TN D-8320, May 1977

12. Anon., Spray Systems Co. Industrial Catalog 50A

13. Fronek, D. L., et. al., "A Distributed Data Acquisition System for Aeronautics Test Facilities", NASA TM 88961 


\begin{tabular}{|c|c|c|c|c|c|c|c|c|c|}
\hline 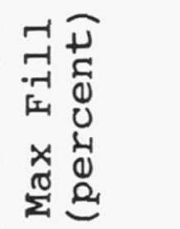 & $\stackrel{-1}{*}$ & ถి & กิ & নँ & бં & హ゙ & নं & హ゙ & ब゙ \\
\hline 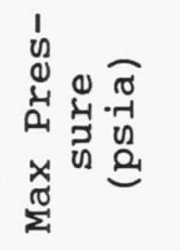 & $\stackrel{r}{\dot{m}}$ & $\begin{array}{l}\text { N } \\
\text { N }\end{array}$ & $\begin{array}{l}\sim \\
\dot{\infty} \\
m\end{array}$ & $\begin{array}{l}\stackrel{0}{~} \\
\stackrel{\sim}{\sim}\end{array}$ & $\begin{array}{l}a \\
\dot{m} \\
m\end{array}$ & $\stackrel{m}{\dot{m}}$ & $\begin{array}{l}\infty \\
\dot{m}\end{array}$ & $\stackrel{\sim}{\stackrel{\sim}{\sim}}$ & $\begin{array}{l}n \\
\dot{0} \\
\dot{m}\end{array}$ \\
\hline 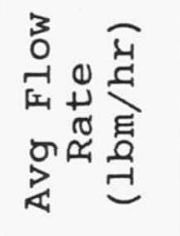 & $\stackrel{\sim}{\sigma}$ & $\begin{array}{l}m \\
\infty \\
m\end{array}$ & $\begin{array}{l}\text { 을 } \\
\text { Mn }\end{array}$ & $\begin{array}{l}a \\
\infty \\
0 \\
ન\end{array}$ & $\begin{array}{l}\infty \\
\stackrel{n}{\sigma}\end{array}$ & $\stackrel{M}{\stackrel{M}{r}}$ & $\begin{array}{l}\hat{\infty} \\
a\end{array}$ & $\begin{array}{l}ન \\
ન \\
ન \\
ન\end{array}$ & 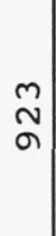 \\
\hline 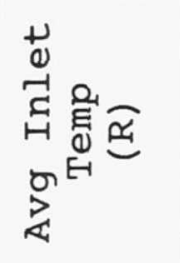 & $\begin{array}{l}0 \\
\dot{-1} \\
\stackrel{\sigma}{*}\end{array}$ & $\begin{array}{l}\mathscr{H} \\
\dot{\sigma}\end{array}$ & $\begin{array}{r}\sim \\
\stackrel{-}{*}\end{array}$ & $\begin{array}{l}0 \\
\dot{\gamma} \\
\dot{*}\end{array}$ & $\begin{array}{l}\vec{\gamma} \\
\dot{\sigma} \\
\dot{\nabla}\end{array}$ & $\begin{array}{l}m \\
\dot{\sigma} \\
\stackrel{\forall}{1}\end{array}$ & $\begin{array}{l}0 \\
\dot{\sigma}\end{array}$ & $\begin{array}{l}0 \\
\text { aे }\end{array}$ & 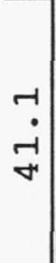 \\
\hline 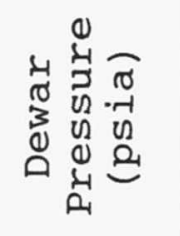 & ○ & 을 & $\stackrel{\circ}{\forall}$ & $\stackrel{n}{\sigma}$ & $\stackrel{n}{\nabla}$ & $\stackrel{\text { In }}{\sigma}$ & $\stackrel{\sim}{\sim}$ & $\stackrel{\sim}{\sim}$ & $\stackrel{\sim}{\sigma}$ \\
\hline 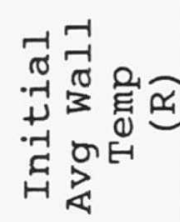 & $\stackrel{\infty}{\infty}$ & $\stackrel{\infty}{m}$ & $\stackrel{-1}{m}$ & a) & $\begin{array}{l}\infty \\
\infty \\
-1\end{array}$ & $\stackrel{\sim}{\sim}$ & $\begin{array}{l}m \\
\infty \\
-1\end{array}$ & $\underset{\sim}{\stackrel{\sim}{\sim}}$ & $\begin{array}{l}0 \\
\stackrel{\sim}{r} \\
-1\end{array}$ \\
\hline 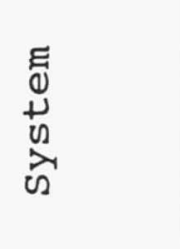 & 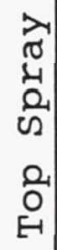 & 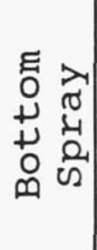 & 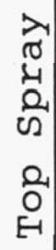 & 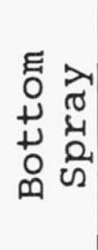 & 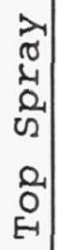 & 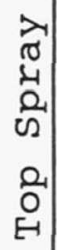 & 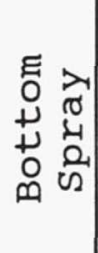 & 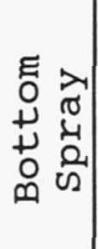 & 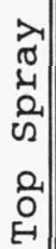 \\
\hline $\begin{array}{l}+ \\
0 \\
0 \\
\text { H }\end{array}$ & $\dashv$ & $\sim$ & $m$ & $\stackrel{\infty}{\sim}$ & $\underset{r-1}{a}$ & $\stackrel{\circ}{\sim}$ & $\stackrel{-1}{\sim}$ & $\underset{\sim}{\sim}$ & $\stackrel{m}{\sim}$ \\
\hline
\end{tabular}




\section{APPENDIX A SECONDARY DATA.}

During the course of testing after the post test clean up for test 17 a leak in the burst disk which provides over pressure protection was discovered. The exact time of occurrence is unknown but the most probable time of origin is during some high pressure excursions following test 3 . The effects of this leakage on the no-vent fill process are uncertain but possibly significantly lower the final fill pressure, therefore tests 4 to 17 have been relegated to this appendix. It is the authors believe that the data in these tests contain some unique information not reproduced in the tests presented in the main body and hence are worthy of documentation with the provisos that absolute pressure levels are not to be trusted and comparisons are made only between similarly affected tests. Table II summarizes these tests.

\section{RESULTS}

To study the effects of liquid presence on the fill process one run with each fill system was started with the tank initially filled to the $50 \%$ level with a 5 psia saturated liquid. Pressure and inlet conditions for a top spray starting at $50 \%$ full and a comparable test starting with a empty tank are shown in figure 25. Pressure and inlet conditions for bottom spray fills starting empty and 50\% full are shown in figure 26 .

As a baseline comparison for assessing the performance of the spray systems, no-vent fills were conducted with the existing 2" fill/drain line from empty and 50\% full. Pressure and inlet conditions for these fills are shown in figure 27.

To increase the flow rate and stabilize the inflow temperature, while the 10 micron filters discussed earlier were still installed, a series of tests were conducted using both the top and bottom spray system simultaneously increasing the overall flow rate to around $1000 \mathrm{lbm} / \mathrm{hr}$. This produced the desired stabilization of inflow temperature so the second series of test objectives investigation of target temperature was commenced. Figure 28 shows the pressure and inlet conditions. For this series, all tests filled to $94 \%$. Increasing start wall temperature lead directly to higher final fill pressures although the result is less pronounced for the $103 \mathrm{R}$ wall start.

After removal of the 10 micron an attempt was made to further stabilize the inlet temperature by allowing some of the liquid hydrogen to exit through the bypass line during the fill. Pressure and inlet conditions resulting from this technique with the top spray and a comparable test without bypass flow are shown in figure 29. About a two degree improvement in subcooling is obtained, however completion of a single fill consumed more than 
half of the hydrogen in the 13,000 gallon hydrogen trailer so further testing with this approach was abandoned as impractical.

Temperature data for tests 4 , and 7 to 17 is not shown due to similarity with the results of more reliable tests. Temperature trends for top spray and bottom spray tests are similar to those discussed for similar tests in the main text. Temperature trends for combined spray are similar to the top spray tests. Tests 5 and 6 for the fill/drain line show the most severe stratification encountered in this test series. The temperature trends shown in figure 30 are for test 6 . Temperature trends for test 5 are similar though not as severe.

\section{DISCUSSION}

Refill of partially full tanks proved easier than complete fill. All three refill tests (tests 4, 5, and 10) filled to maximum, whereas the comparable complete fills (tests 13, 6 and 11, respectively) were terminated prior to maximum fill.

Inlet subcooling seems the principle problem of the no-vent fill process. The combined fills with their more stable inlet temperatures are much more successful than either spray system alone at the reduced flow rate. The effect of inlet subcooling can be clearly seen in figure 29 where the major difference in technique is an improvement of the subcooling with bypass flow.

Using the fill/drain line without a spray system does not look attractive. Although the fill/drain system does not suffer the subcooling problems of the spray systems (and possible help from burst disk leakage), it was only capable of a $70 \%$ fill starting from empty. The refill testing does suggest an option if a fill/drain system must used. Fill the tank partially with a nonvented fill. Reduce tank pressure with controlled venting to space, then fill again.

Table 2 K-Site Phase IA Secondary Test Runs

\begin{tabular}{|c|c|c|c|c|c|c|c|}
\hline Test & System & $\begin{array}{c}\text { Inltial } \\
\text { Avg Wall } \\
\text { Temp } \\
\text { (R) }\end{array}$ & $\begin{array}{l}\text { Dewar } \\
\text { Pressure } \\
\text { (psia) }\end{array}$ & $\begin{array}{l}\text { Avg Inlet } \\
\text { Temp } \\
\text { (R) }\end{array}$ & $\begin{array}{c}\text { Avg Flow } \\
\text { Rate } \\
(1 \mathrm{bm} / \mathrm{hr})\end{array}$ & $\begin{array}{l}\text { Max } \\
\text { Pressure } \\
\text { (psia) }\end{array}$ & $\begin{array}{l}\text { Max Fill } \\
\text { (percent) }\end{array}$ \\
\hline 4 & Top Spray & 32 & 45 & 40.9 & 393 & 42.9 & 87 \\
\hline 5 & F111/Drain" & 37 & 45 & 36.7 & 1868 & 19.6 & 94 \\
\hline 6 & F11l/Drain & 37 & 45 & 38.6 & 1430 & 45.7 & 74 \\
\hline 7 & Combined & 31 & 45 & 39.5 & 825 & 31.3 & 94 \\
\hline 8 & Combined & 103 & 45 & 41.4 & 973 & 30.7 & 94 \\
\hline 9 & Combined & 188 & 45 & 40.2 & 844 & 42.1 & 94 \\
\hline 10 & Bottom Jet ${ }^{\circ}$ & 33 & 45 & 39.8 & 462 & 18.1 & 94 \\
\hline 11 & Bottom Jet & 29 & 45 & 40.9 & 406 & 42.1 & 94 \\
\hline $11 \mathrm{~A}$ & Combined & 29 & 45 & 39.5 & 1005 & 26.5 & 94 \\
\hline 12 & Combined & 217 & 45 & 40.4 & 641 & 45.2 & 92 \\
\hline 13 & Top spray & 30 & 45 & 42.0 & 350 & 39.5 & 44 \\
\hline 15 & Top spray & 33 & 45 & 39.1 & 869 & 21.9 & 94 \\
\hline 17 & Top Spray & 34 & 45 & 41.4 & 927 & 29.4 & 94 \\
\hline
\end{tabular}

"Test started $1 / 2$ full of 11 quid at 5 psia pressure 


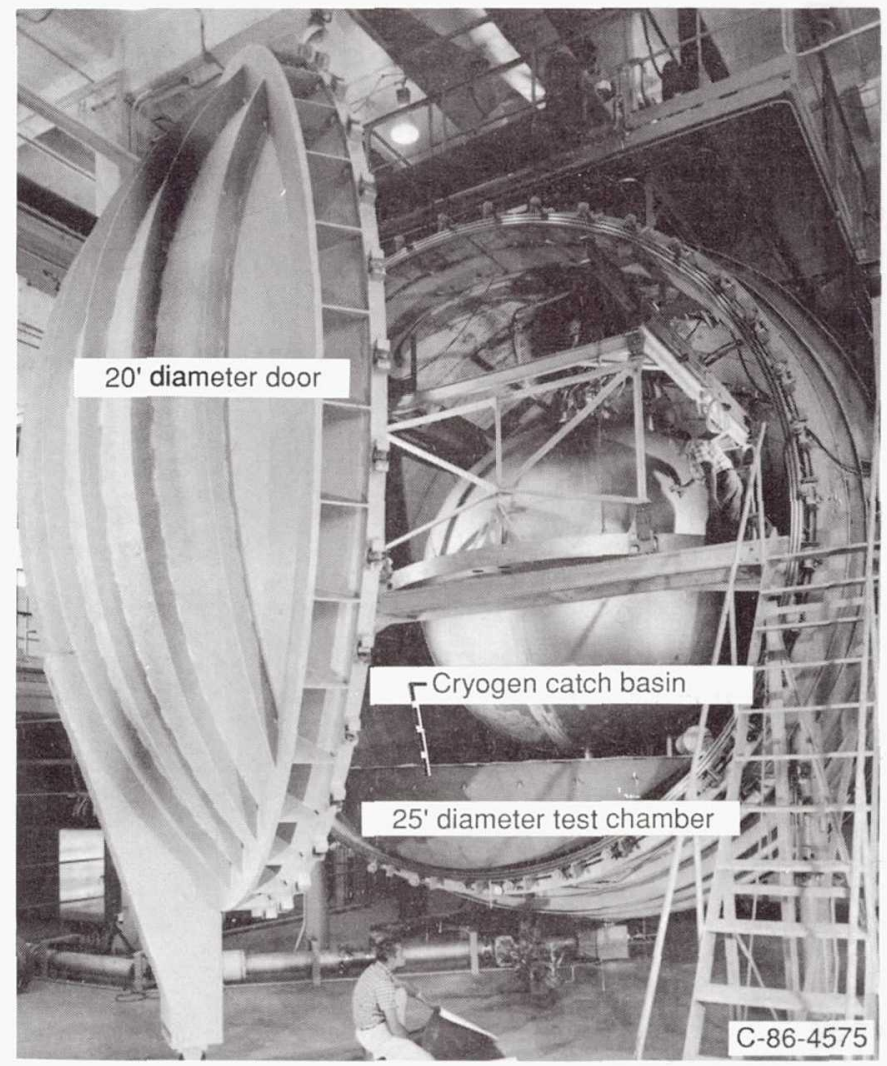

Figure 1.-K-Site vacuum chamber. 


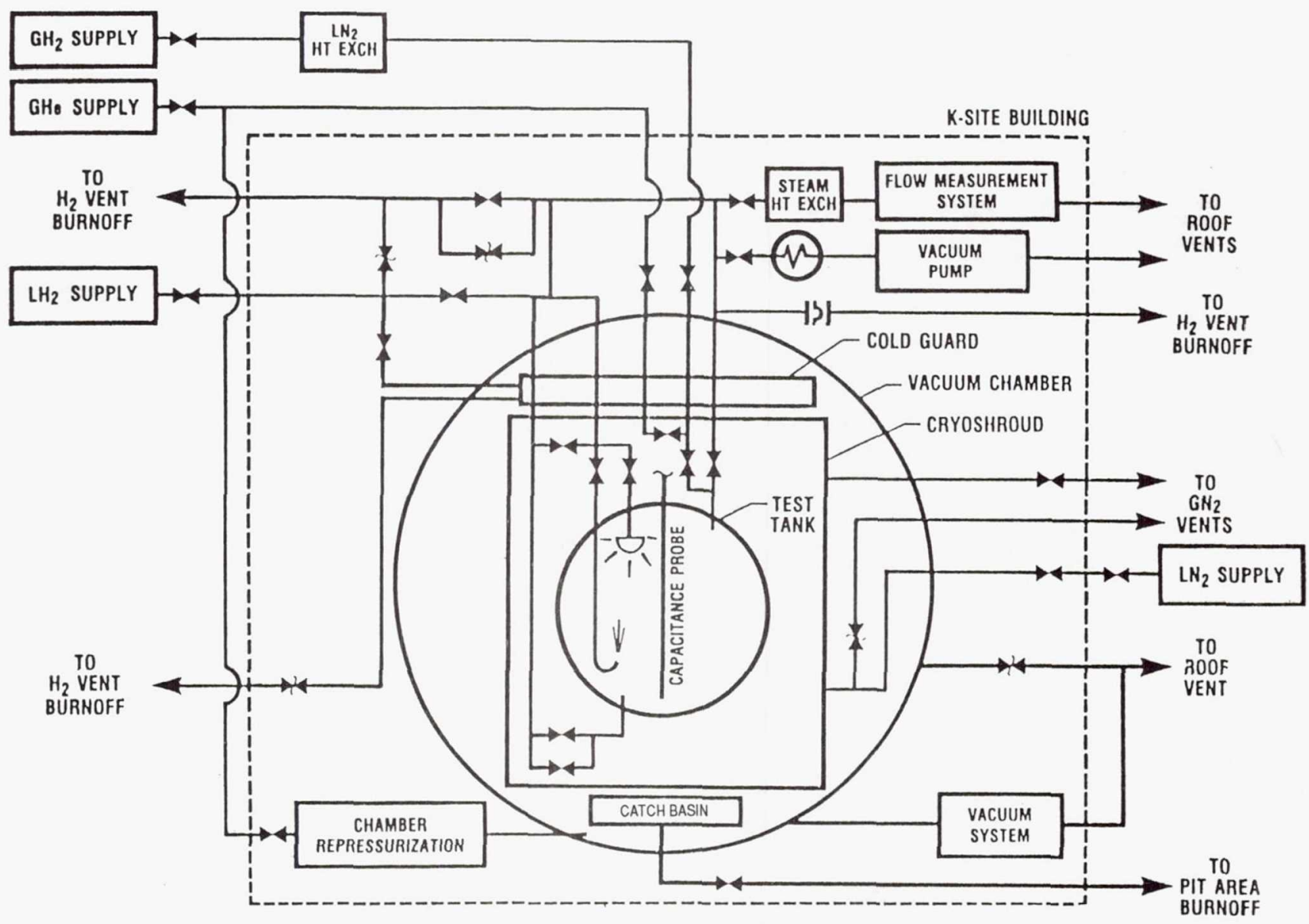

Figure 2.-K-Site simplified facility schematic with research hardware.

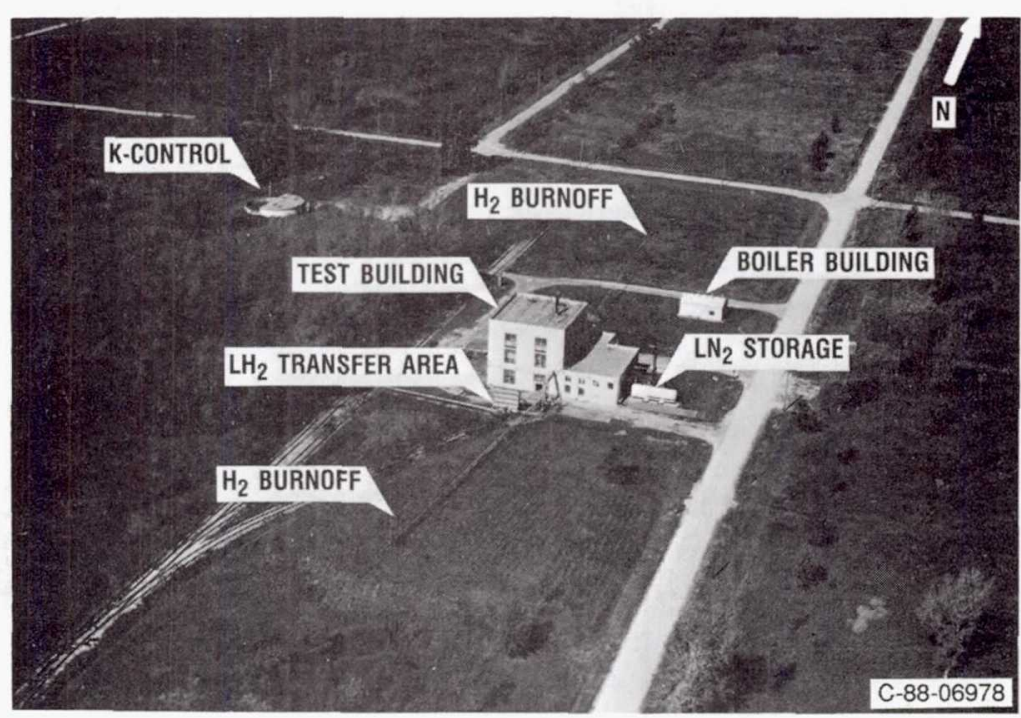

Figure 3.-Aerial view of K-Site. 


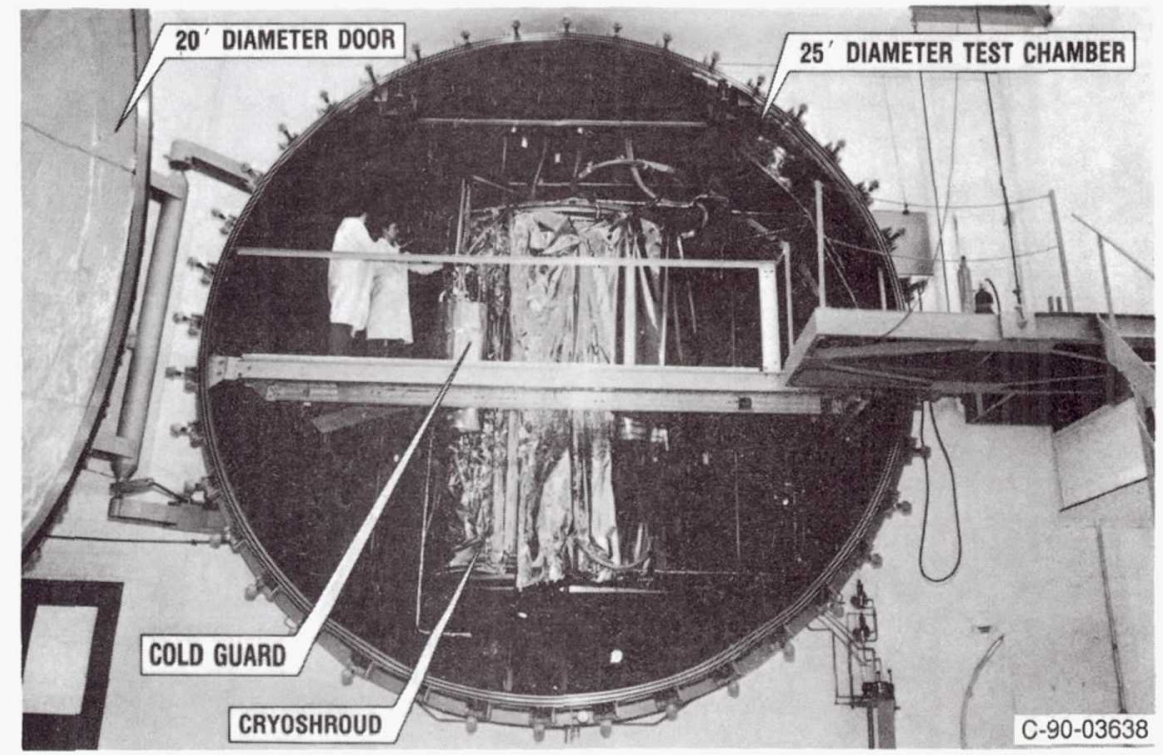

Figure 4.-View of inside chamber with cryoshround around $\mathrm{LH}_{2}$ test tank.

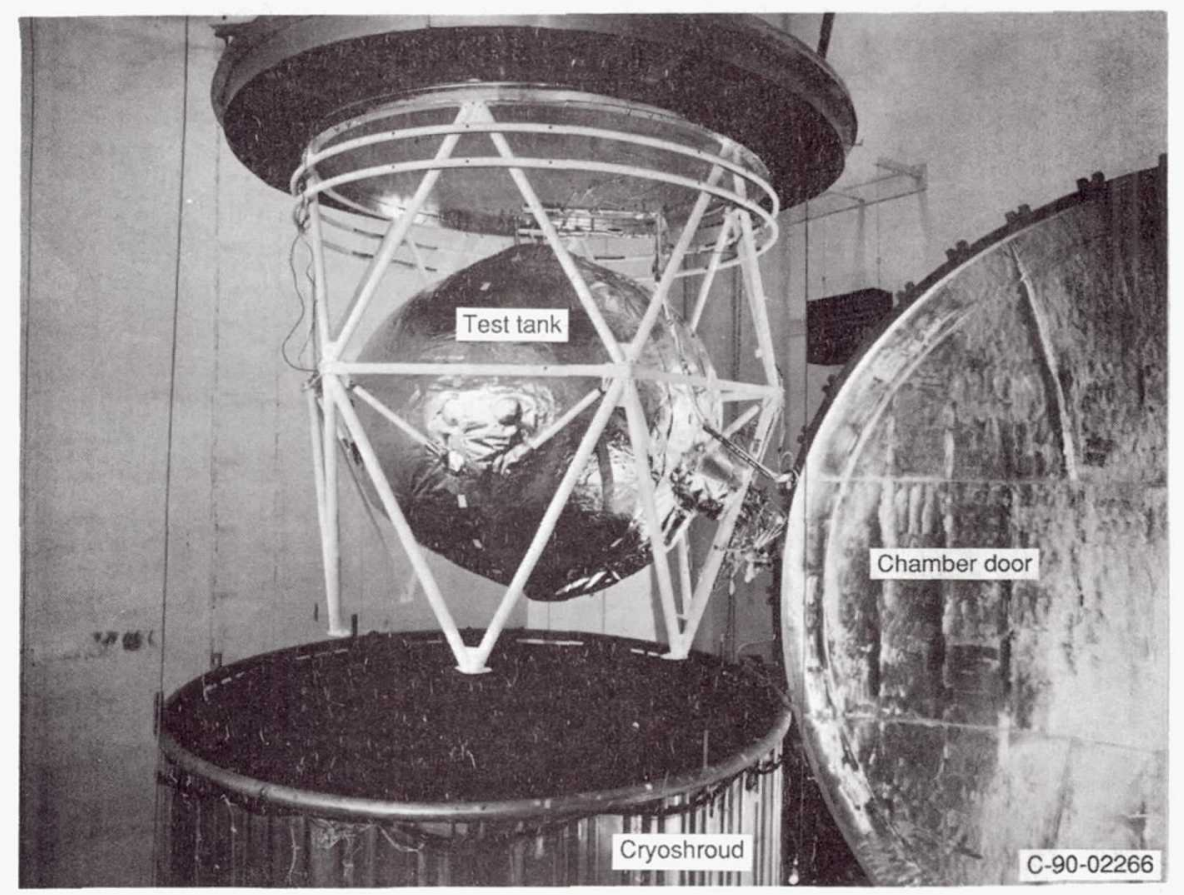

Figure 5.-Test tank suspended over cryoshroud. 


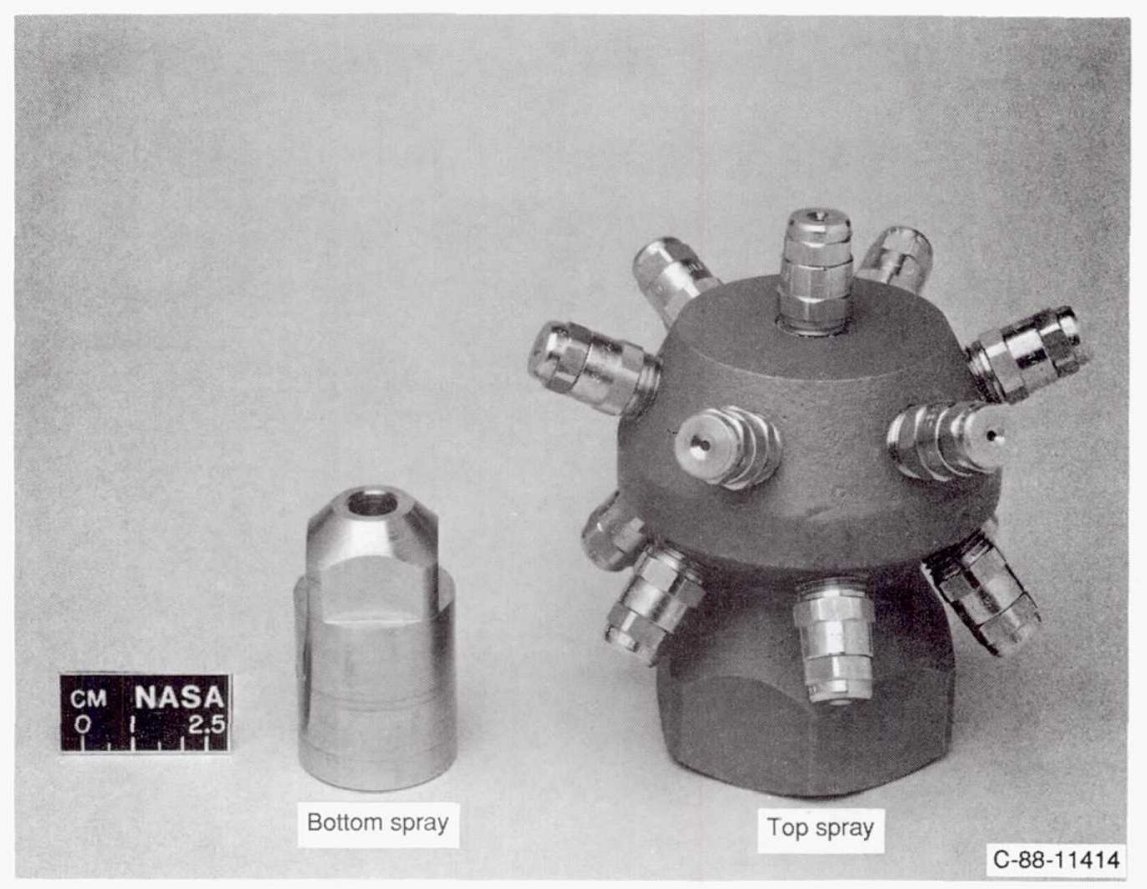

Figure 6.-Spray nozzles.

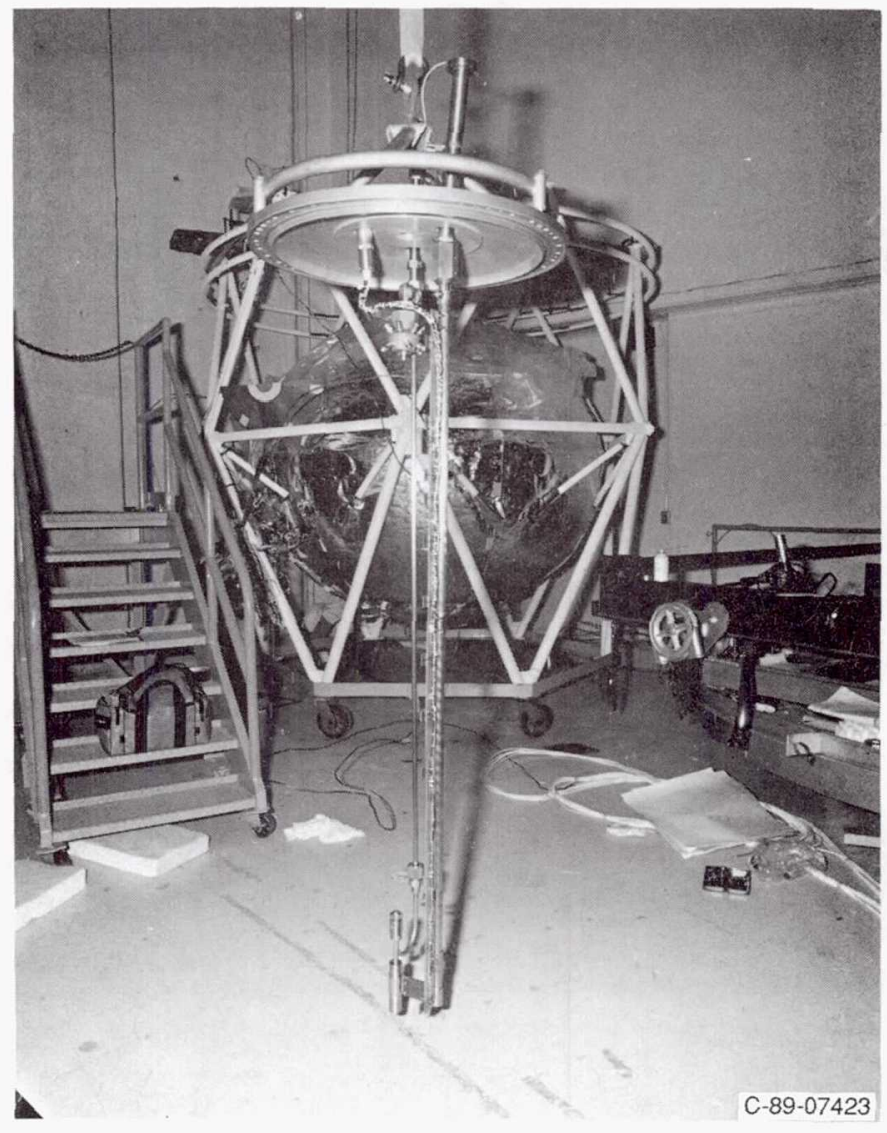

Figure 7.-Spray nozzles installed on tank lid. 


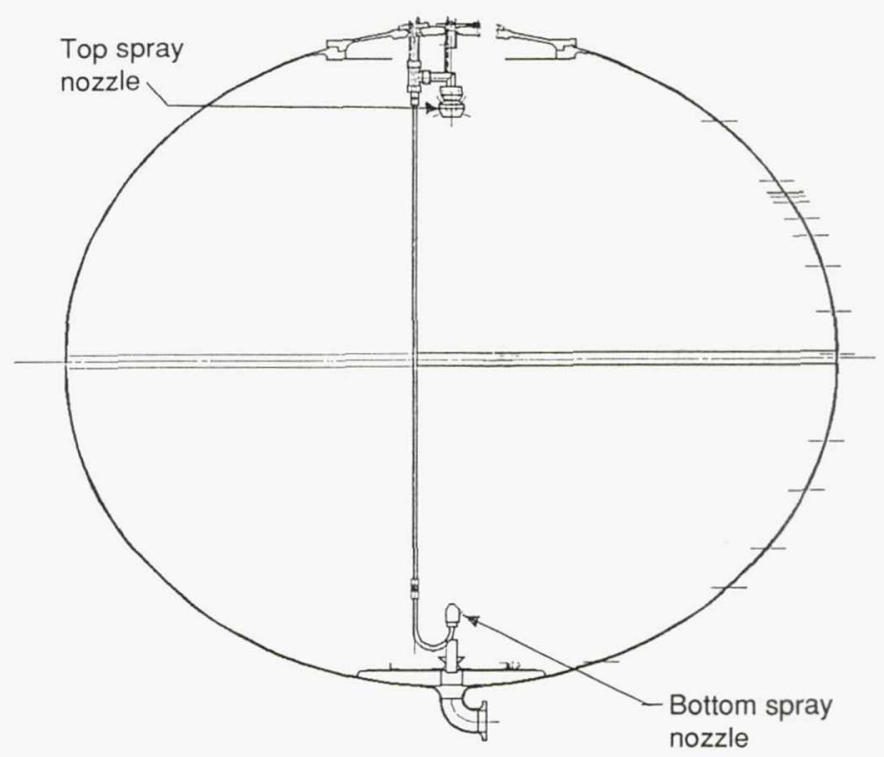

Figure 8.-Spray nozzles installed in tank.

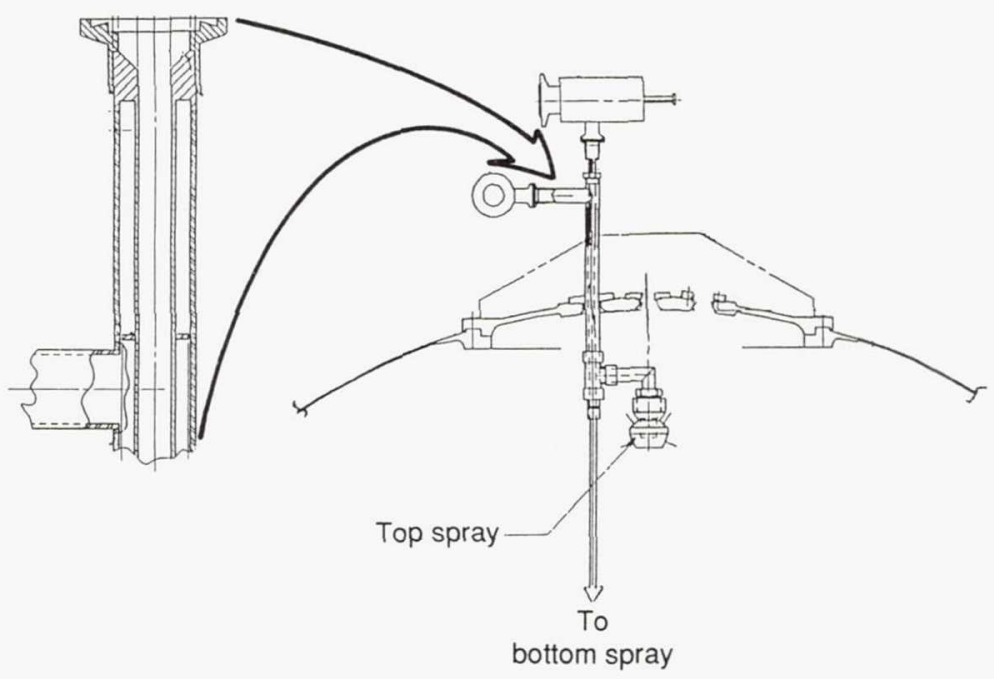

Figure 9.-Concentric tube feedthrough for spray system. 


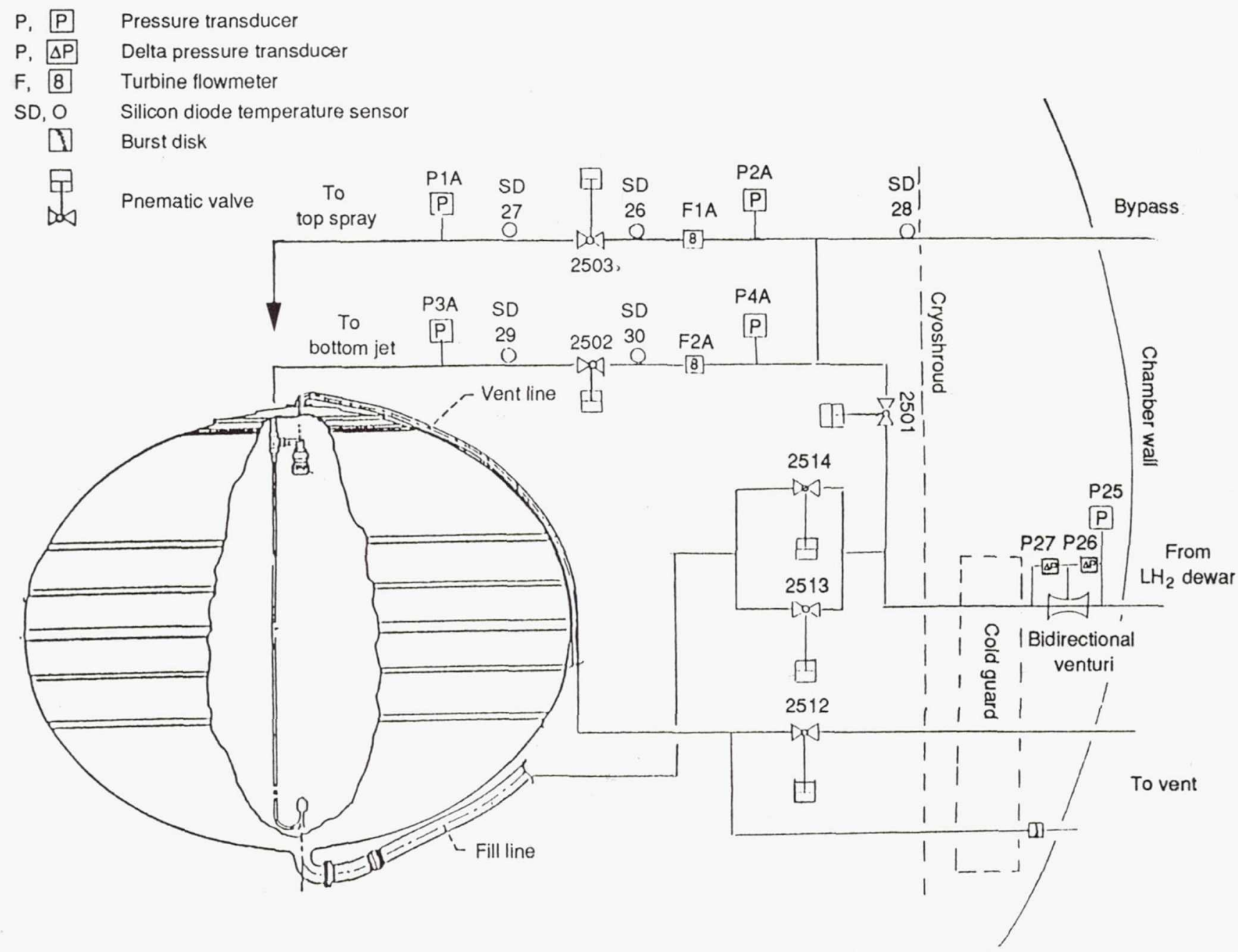

Figure 10. Schematic of hydrogen lines in chamber. 


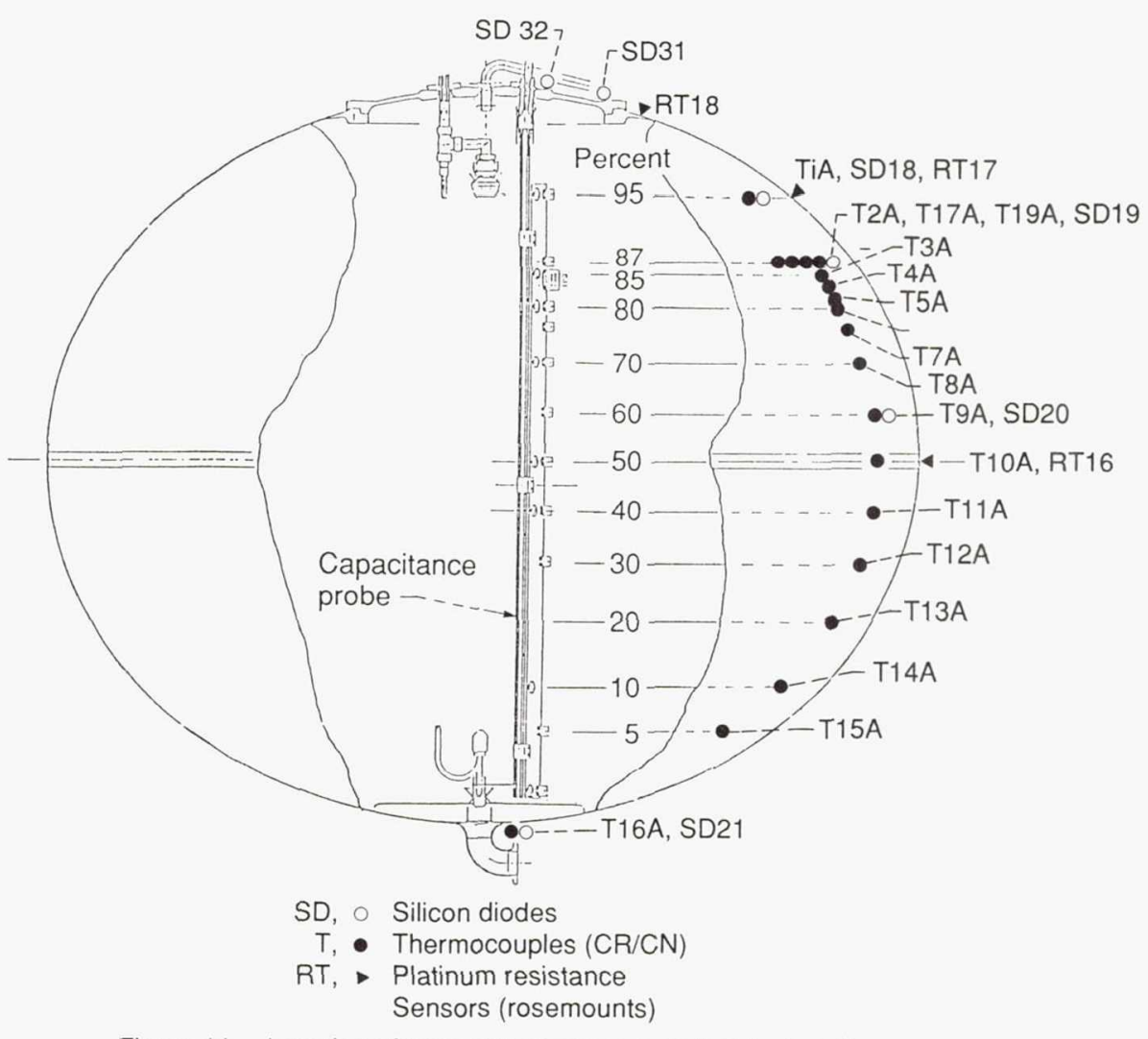

Figure 11.-Location of temperature sensors on test tank wall. 


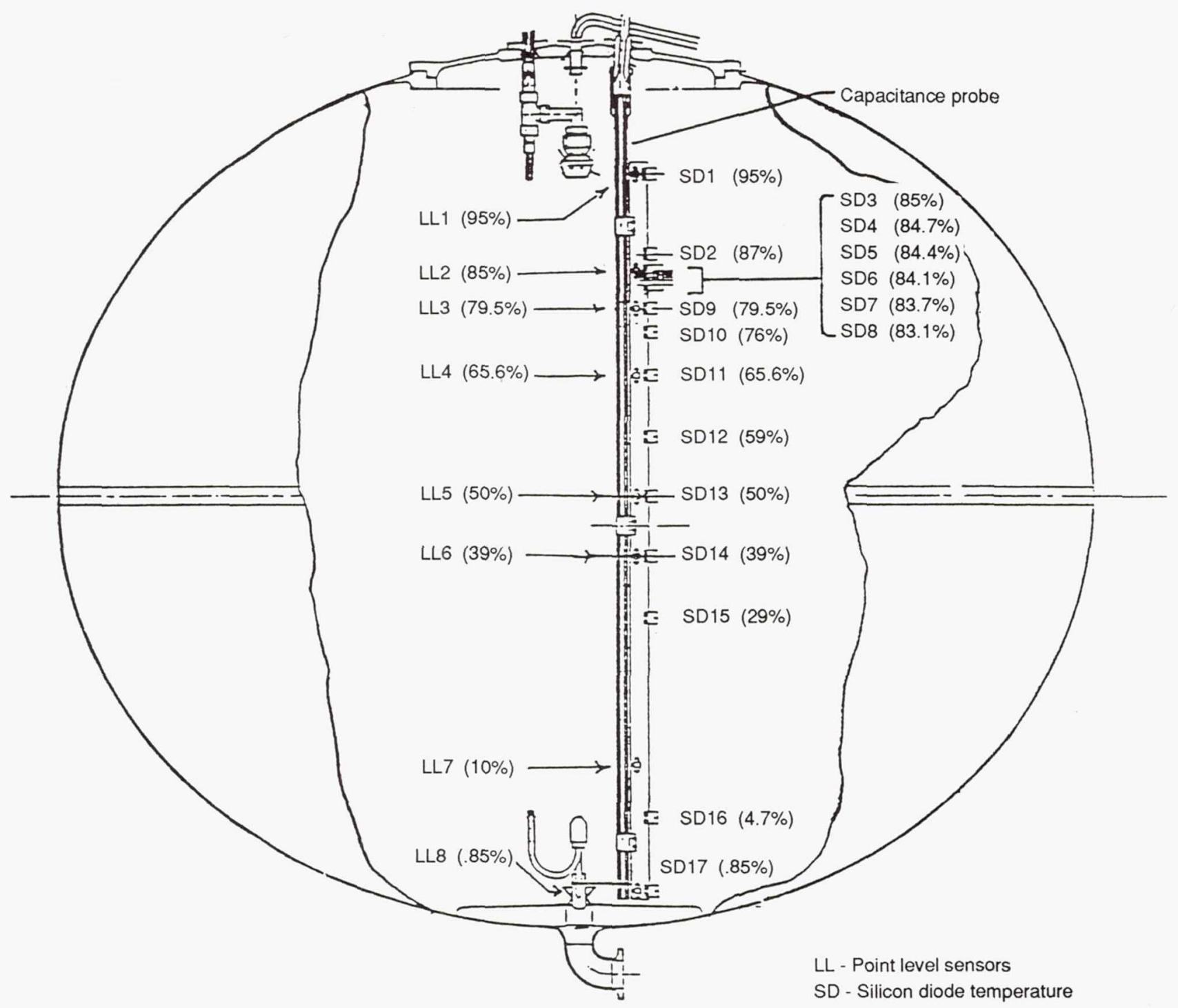

Figure 12.- Internal tank instrumentation (capacitance probe, point level sensors, and temperatures) 

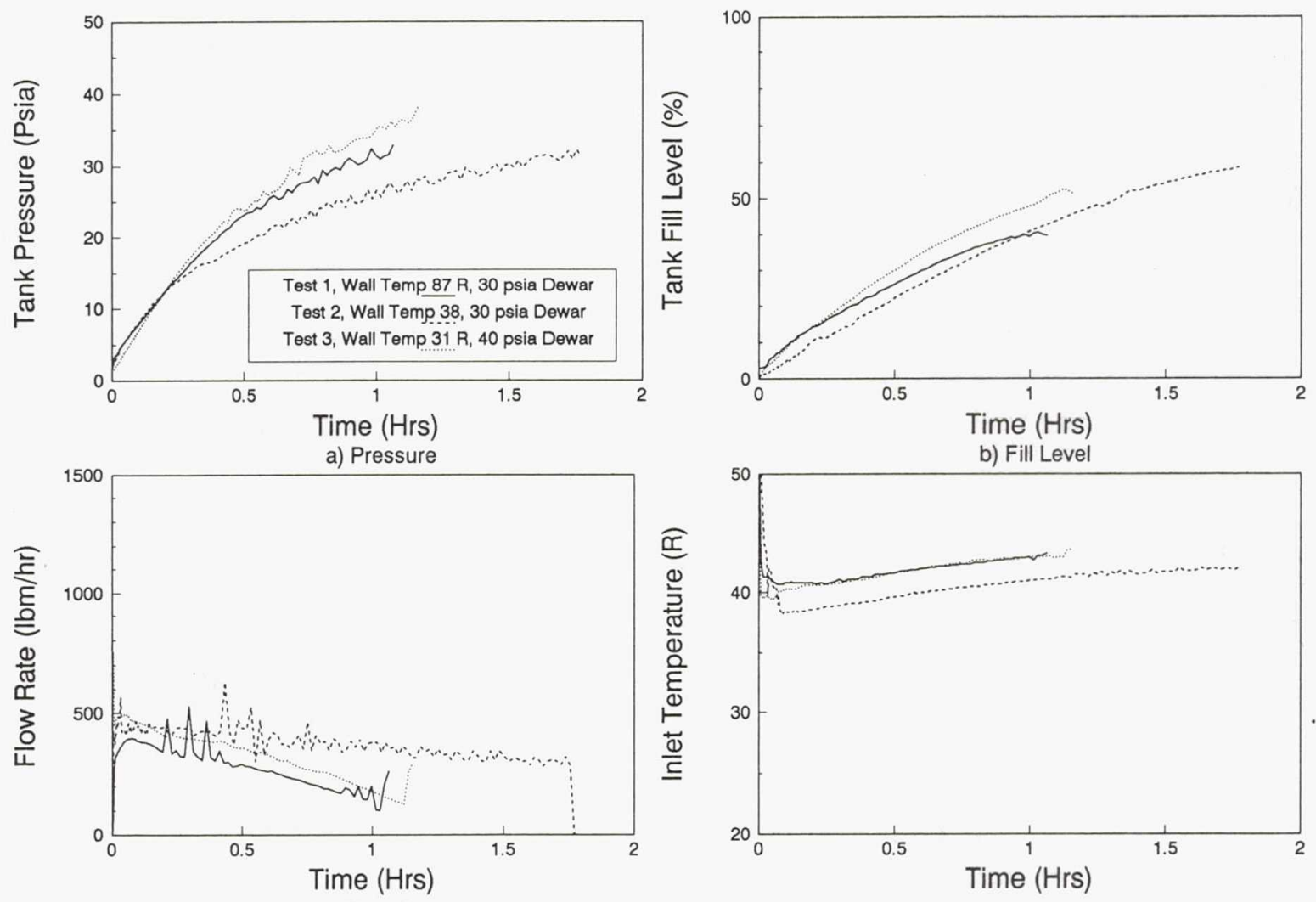

b) Fill Level

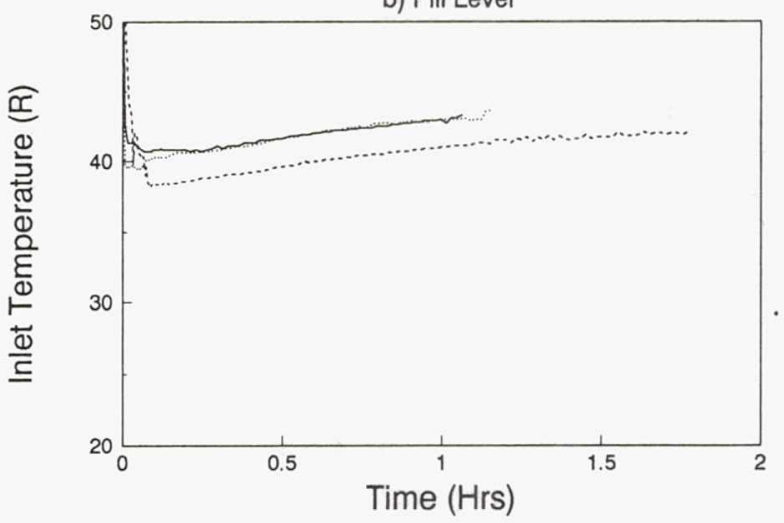

c) Flow Rate

d) Inlet Temperature

Figure 13.-Pressure and inlet conditions for initial fill tests.
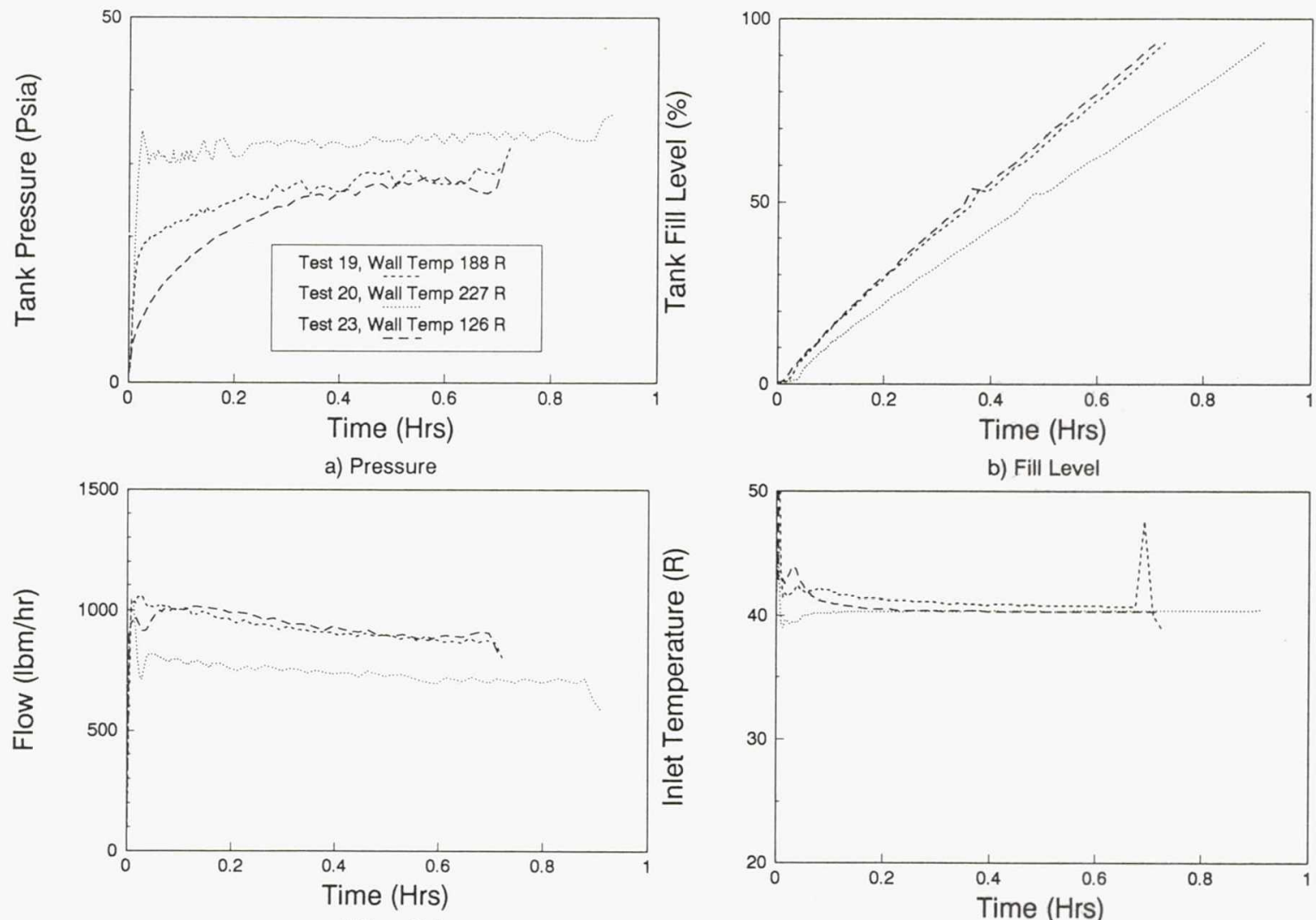

b) Fill Level

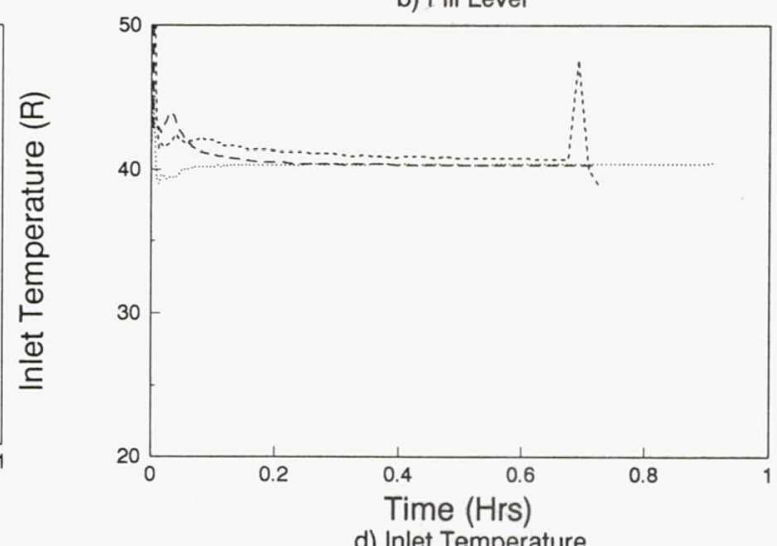

c) Flow Rate

d) Inlet Temperature

Figure 14.-Pressure and inlet conditions for high flow top spray tests. 


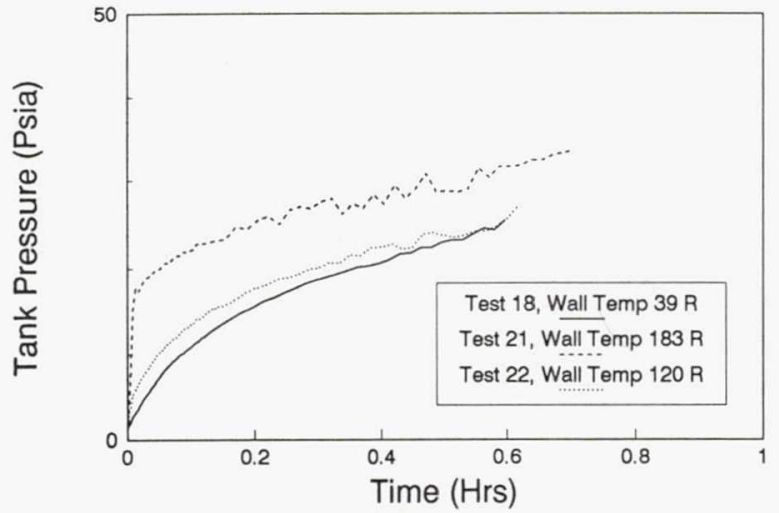

a) Pressure

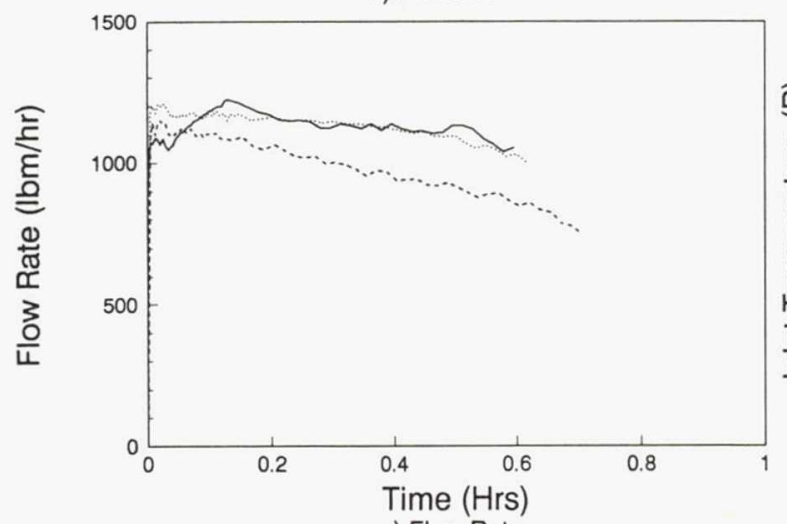

c) Flow Rate

Figure 15.-Pressure and inlet conditions for high flow bottom spray tests.

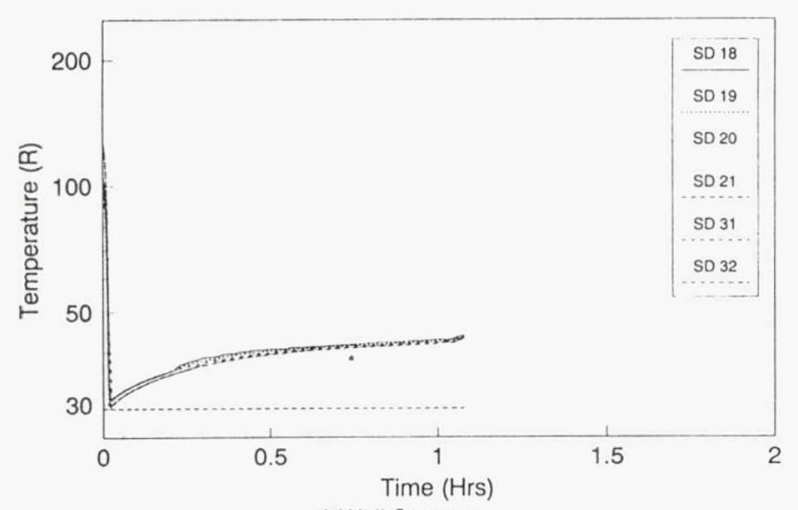

a) Wall Sensors

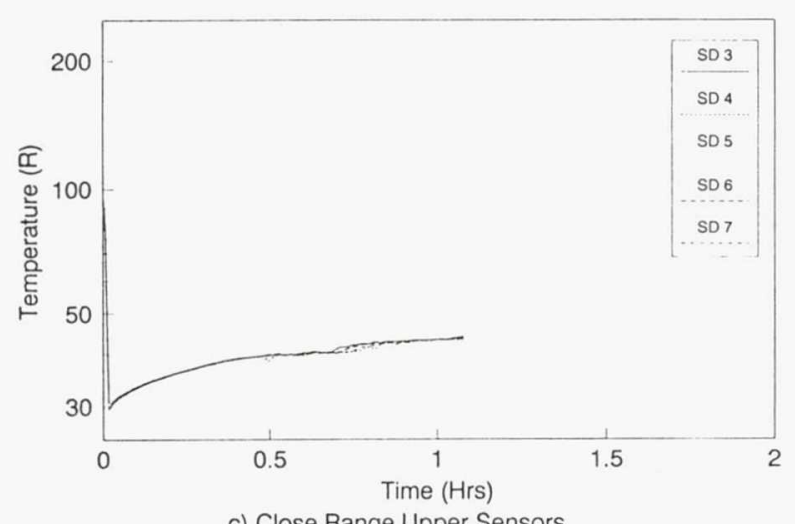

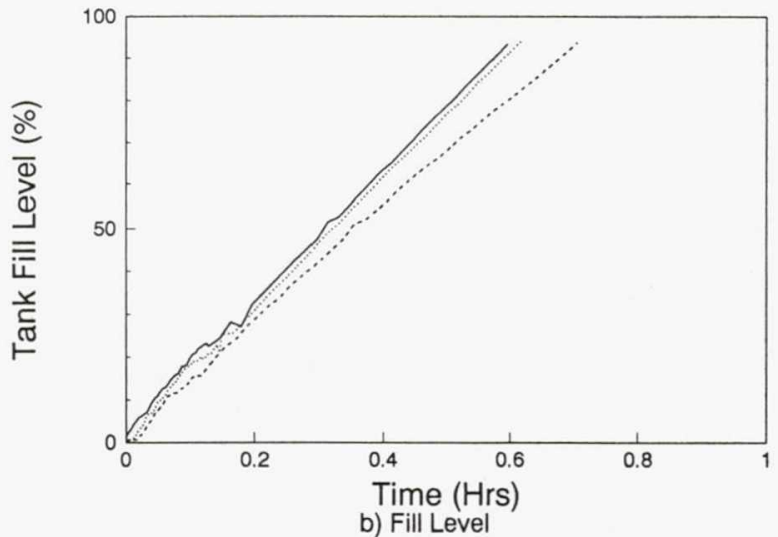

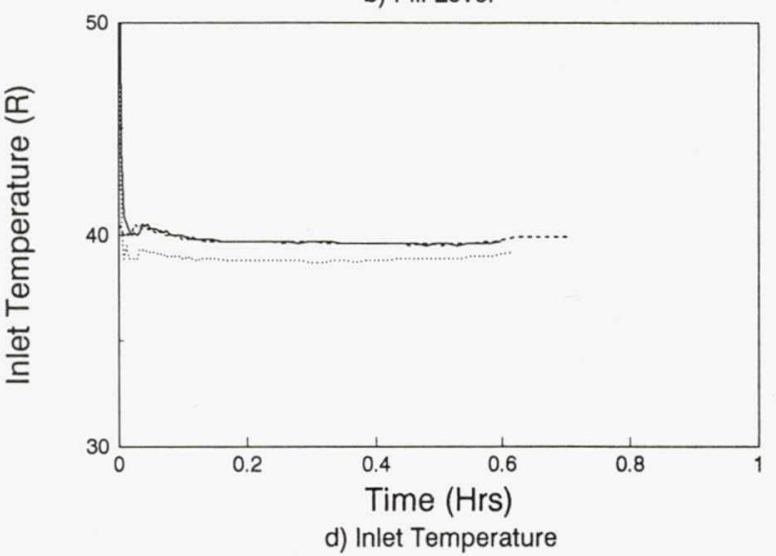

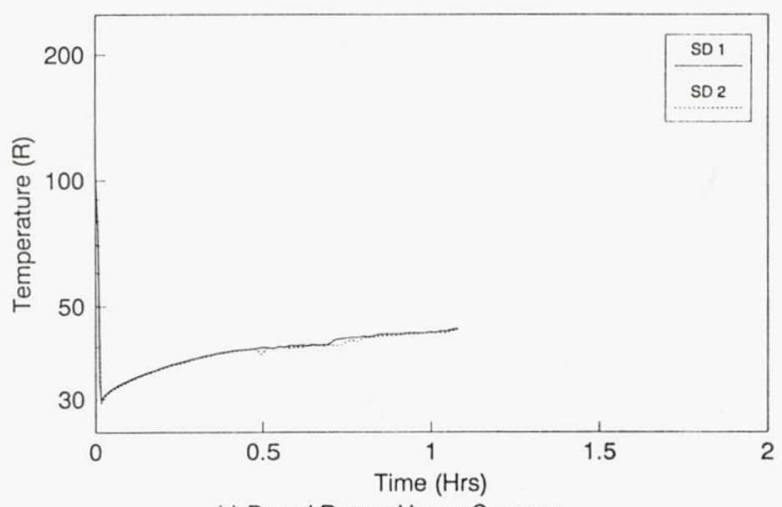

b) Broad Range Upper Sensors

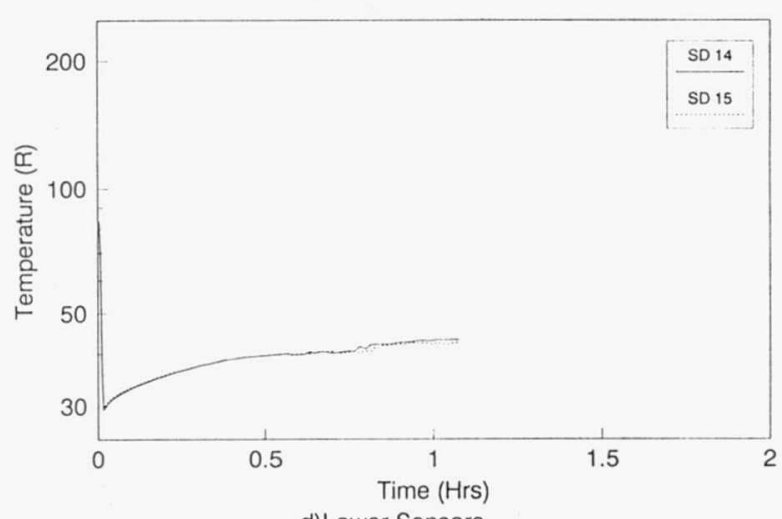

d)Lower Sensors

Figure 16.-Temperatures for test 1. 


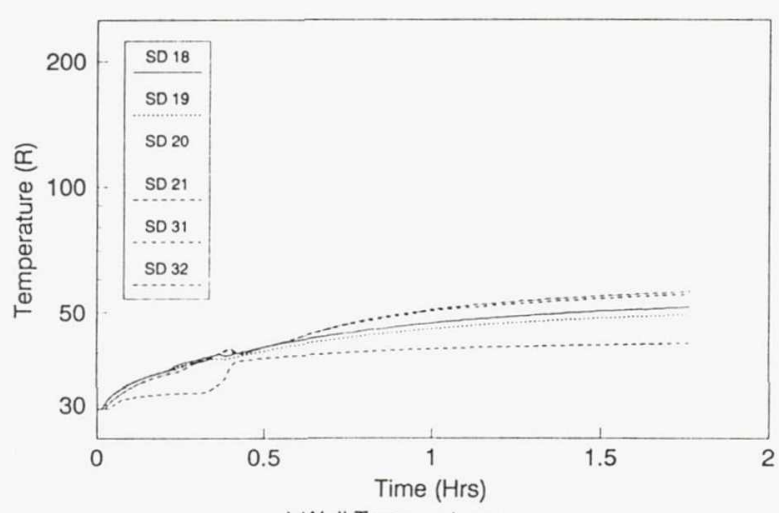

a) Wall Temperatures

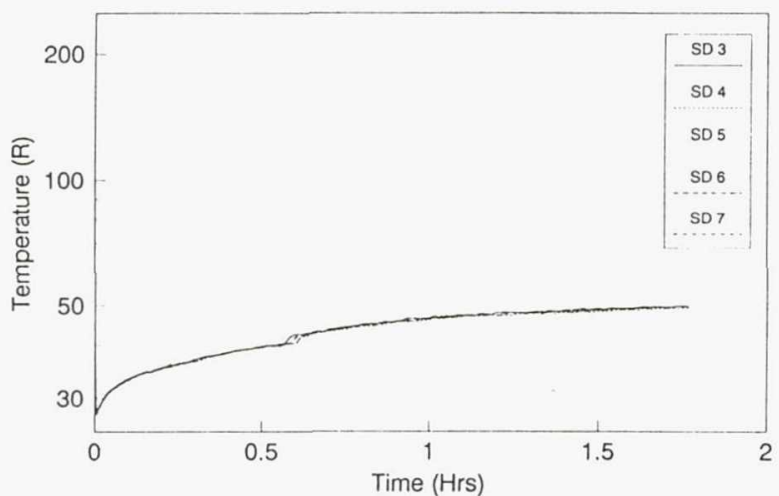

C) Close Range Upper Sensors

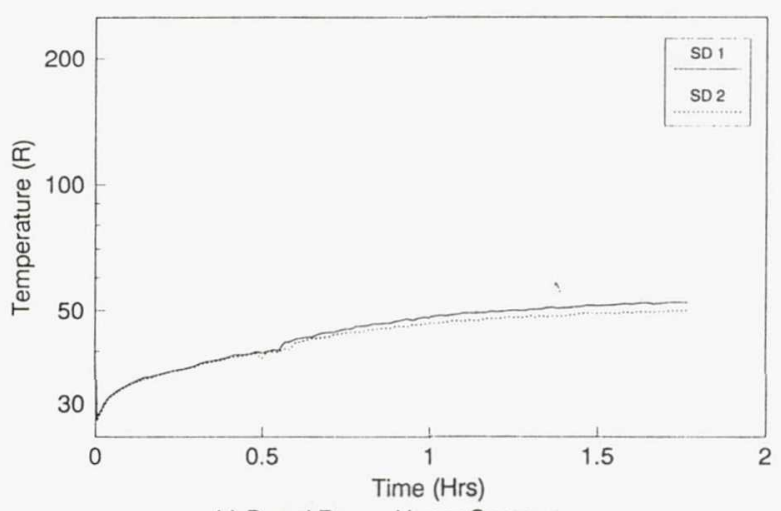

b) Broad Range Upper Sensors

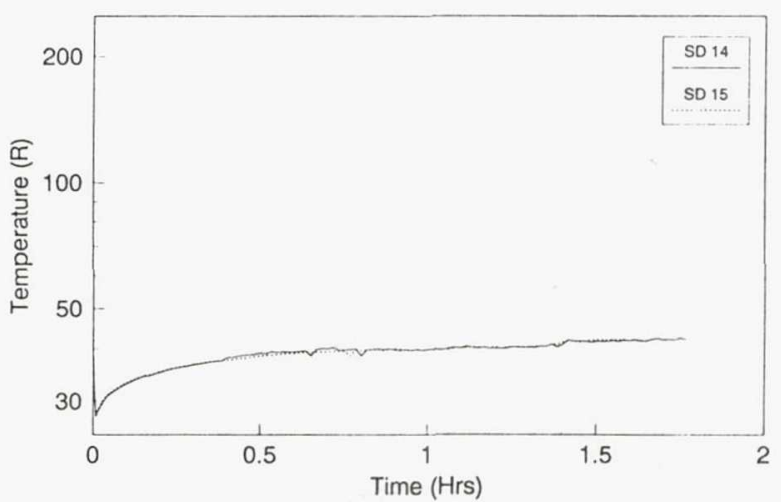

d) Lower Sensors

Figure 17.-Temperatures for test 2.

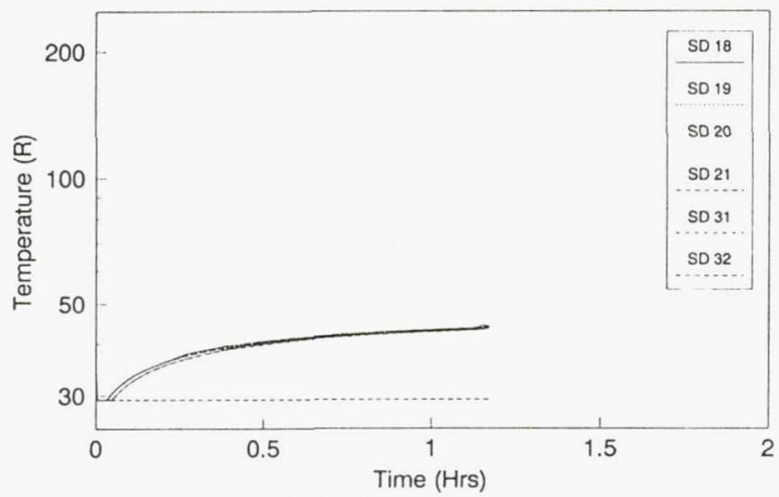

a) Wall Temperatures

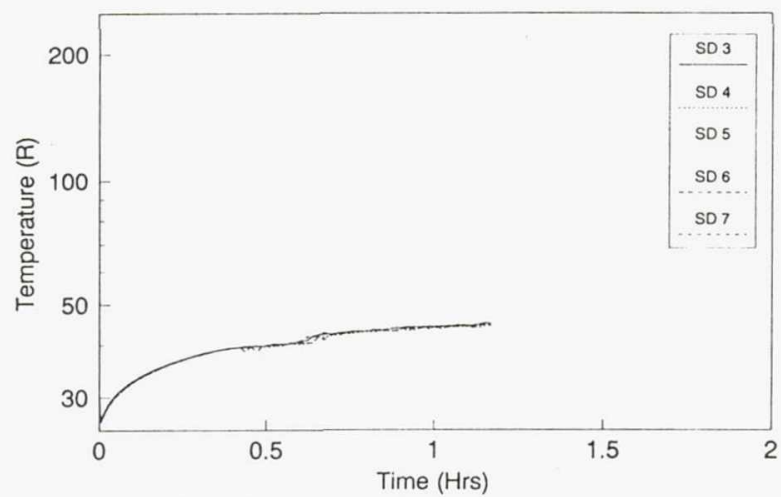

c) Close Range Upper Internal Temperatures

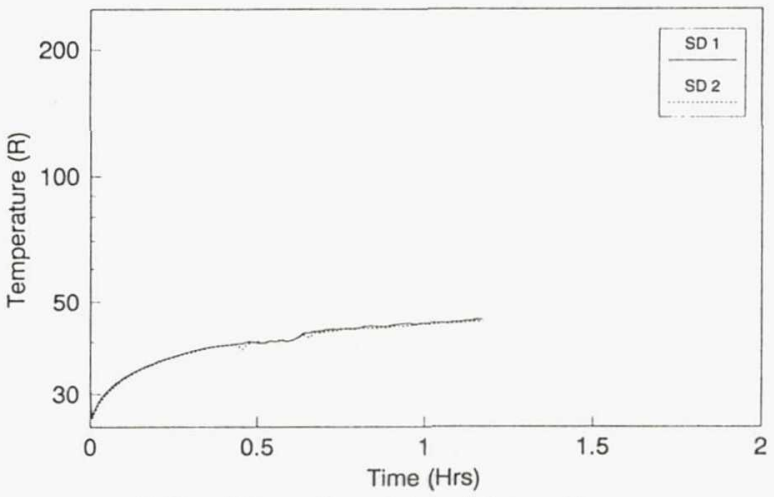

b) Broad Range Upper Internal Temperatures

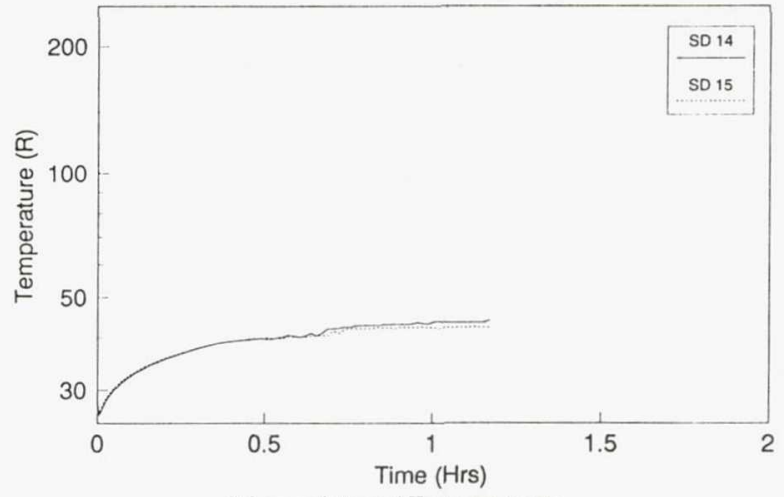

d) Lower Internal Temperatures

Figure 18.-Temperatures for test 3. 


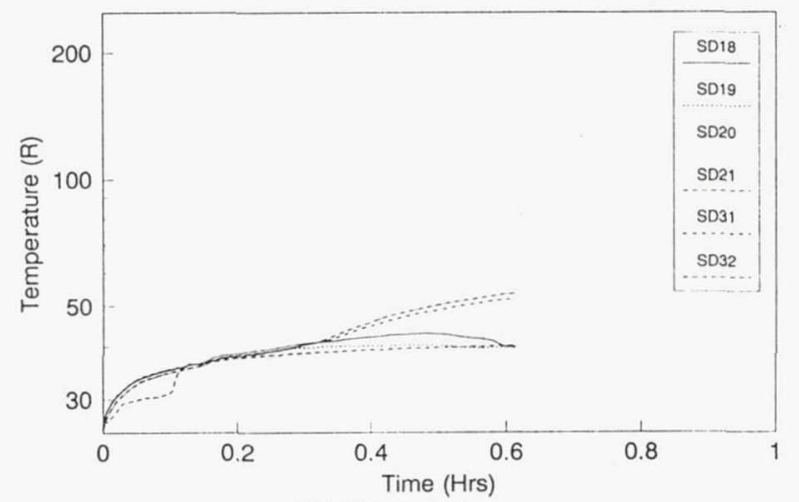

a) Wall Temperatures

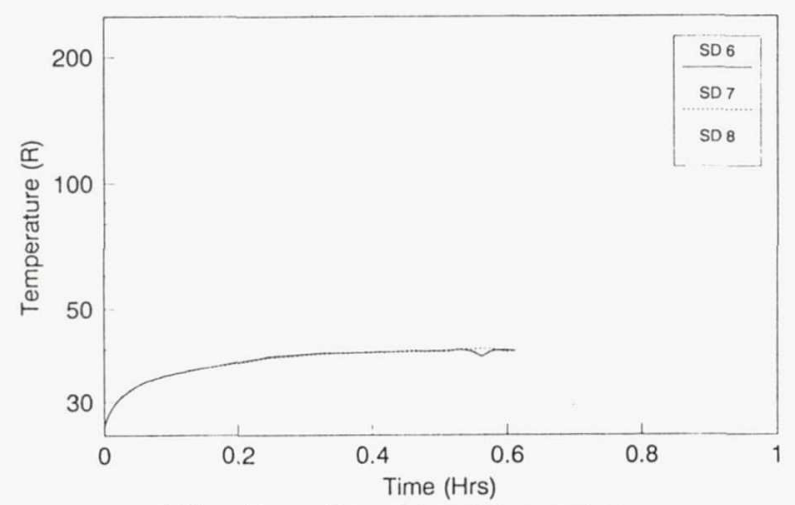

c) Close Range Upper Internal Temperatures

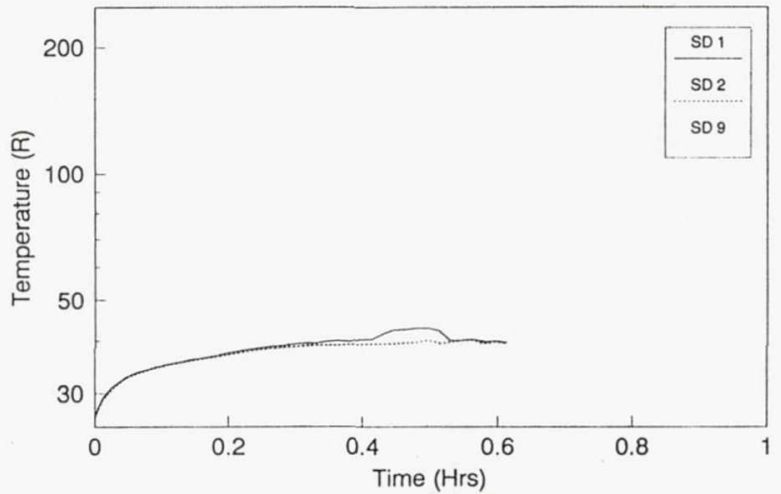

b) Broad Range Upper Internal Temperatures

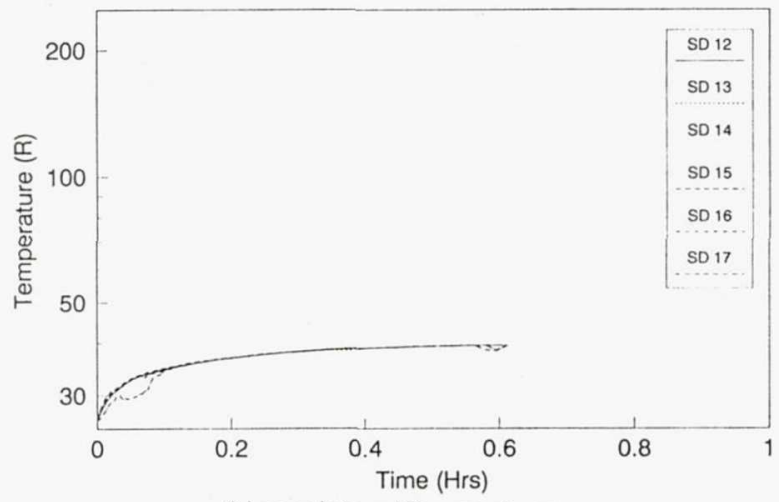

d) Lower Internal Temperatures

Figure 19.--Temperatures for test 18.

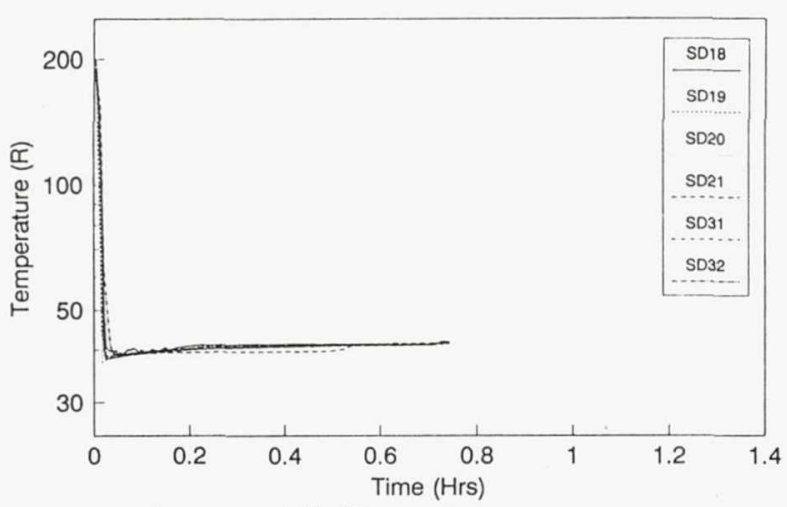

a) Wall Temperatures

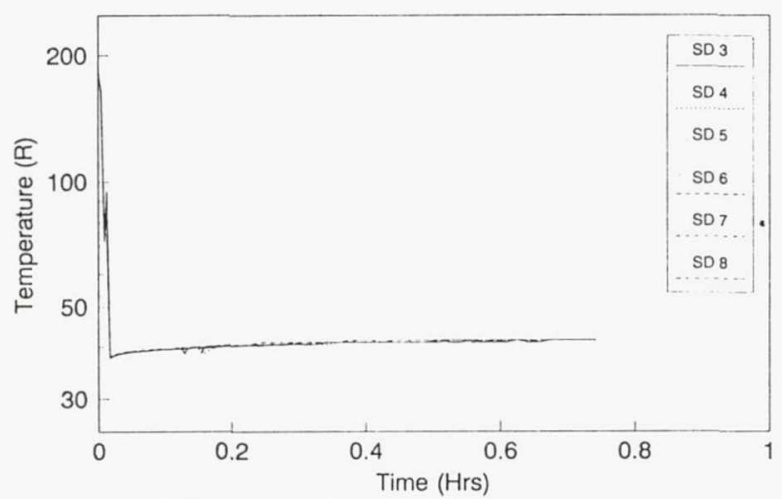

c) Close Range Upper Internal Temperatures

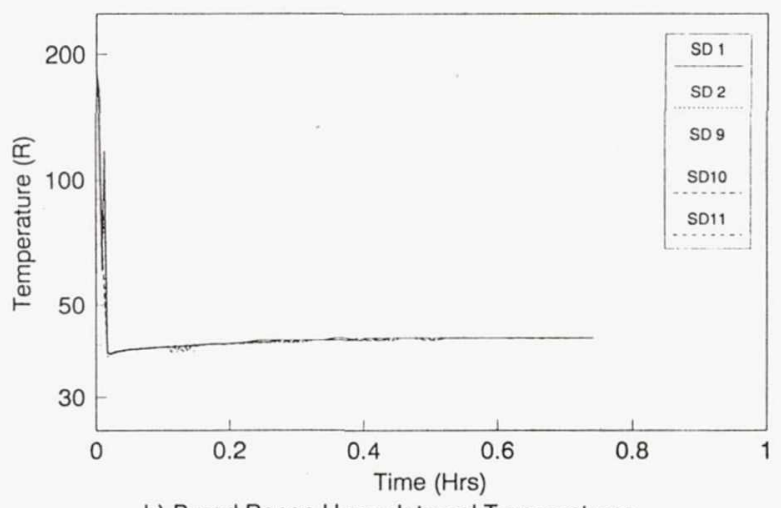

b) Broad Range Upper Internal Temperatures

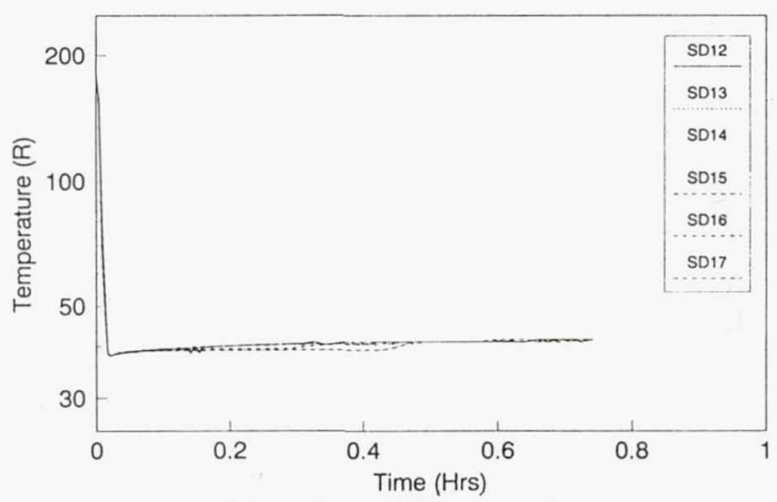

d) Lower Internal Temperatures

Figure 20.-Temperatures for test 19. 


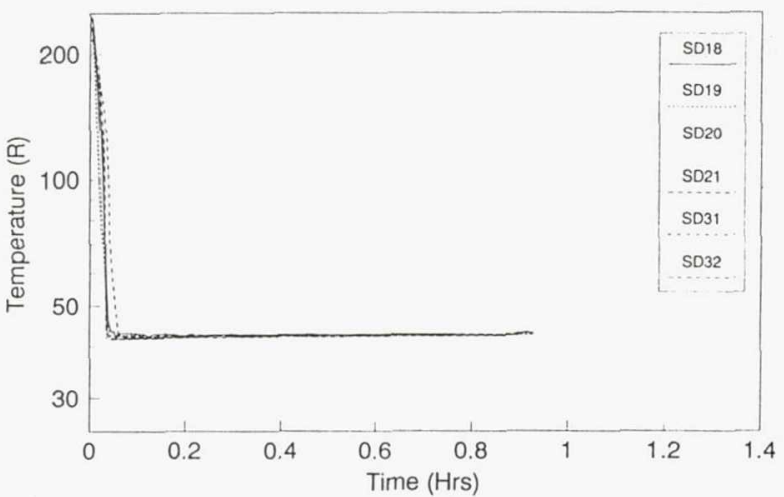

a) Wall Temperatures

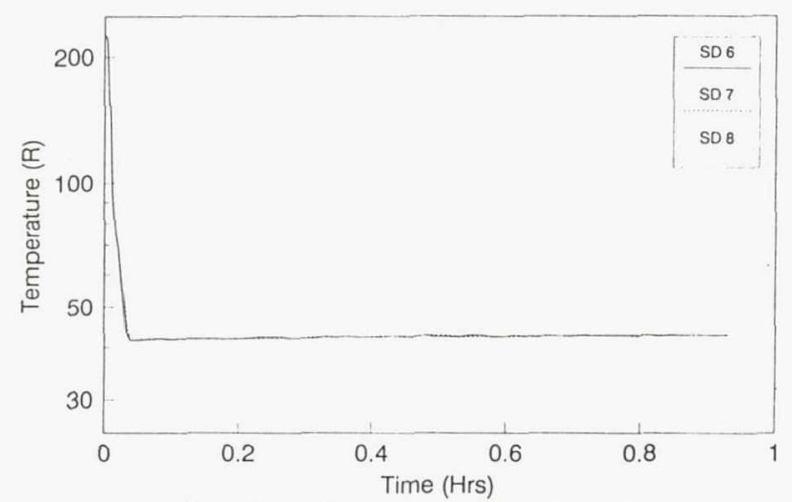

c) Close Range Upper Internal Temperatures

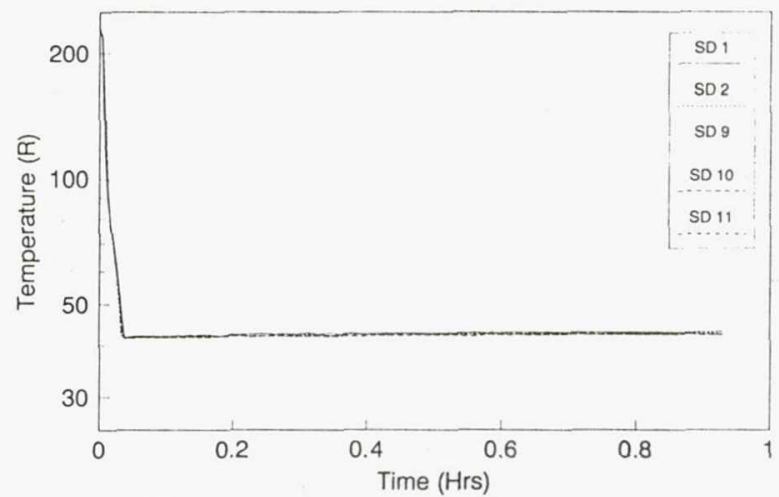

b) Broad Range Upper Internal Temperatures

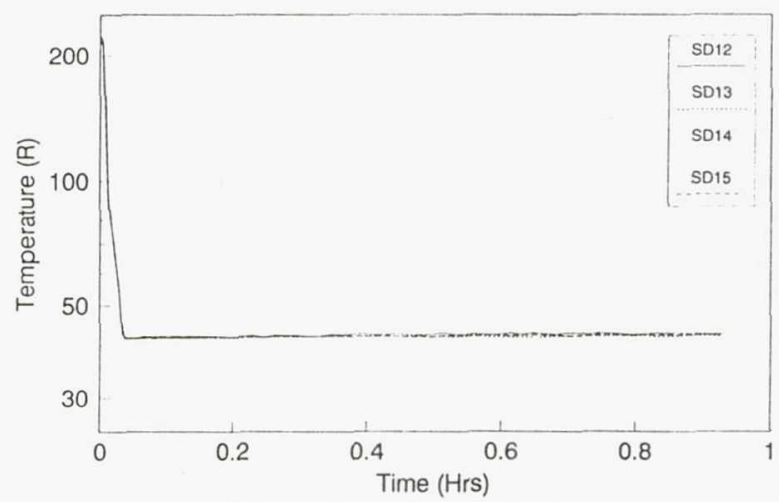

d) Lower Internal Temperatures

Figure 21.-Temperatures for test 20.

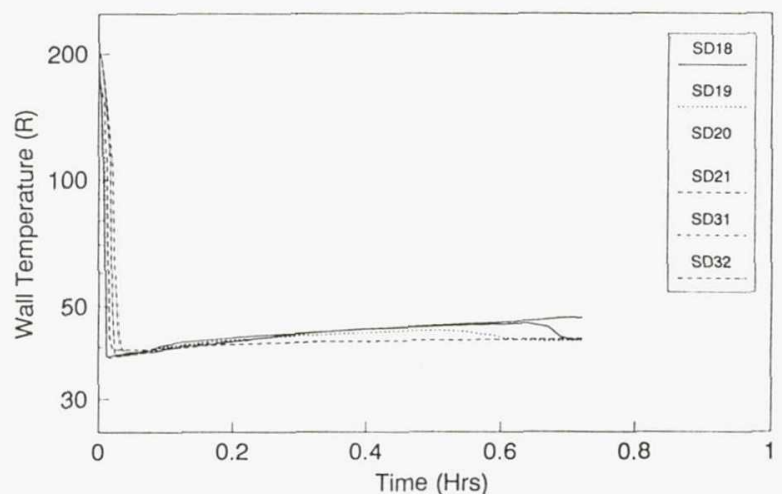

a) Wall Temperatures

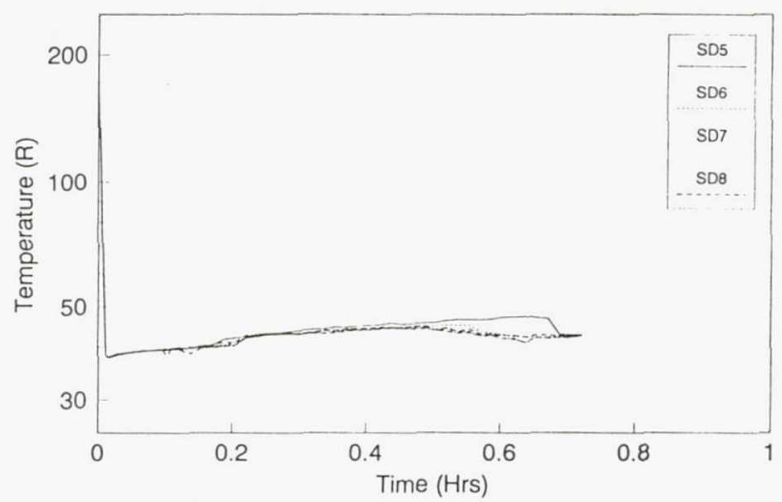

c) Close Range Upper Internal Temperatures

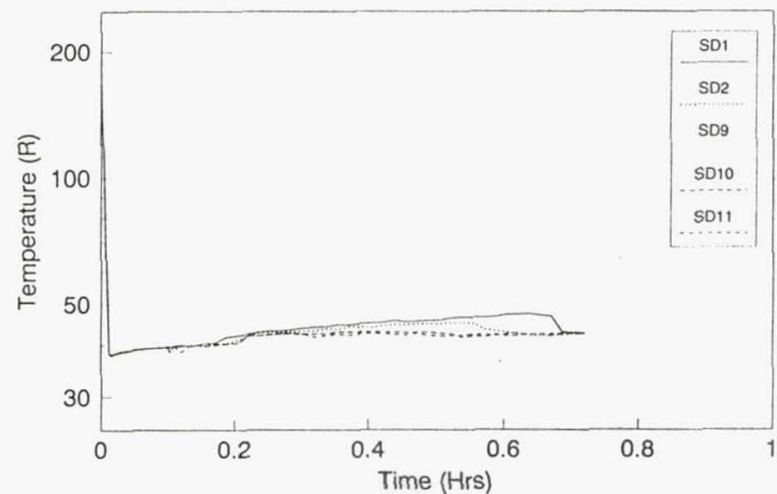

b) Broad Range Upper Internal Temperatures

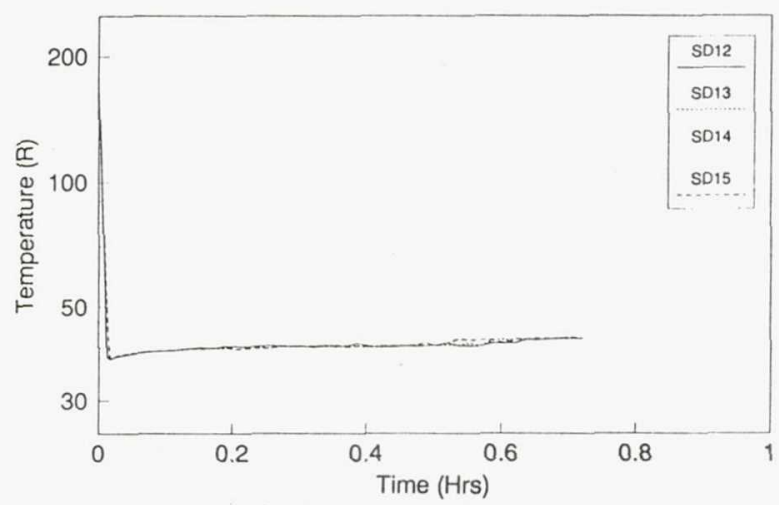

d) Lower Internal Temperatures

Figure 22.-Temperatures for test 21. 


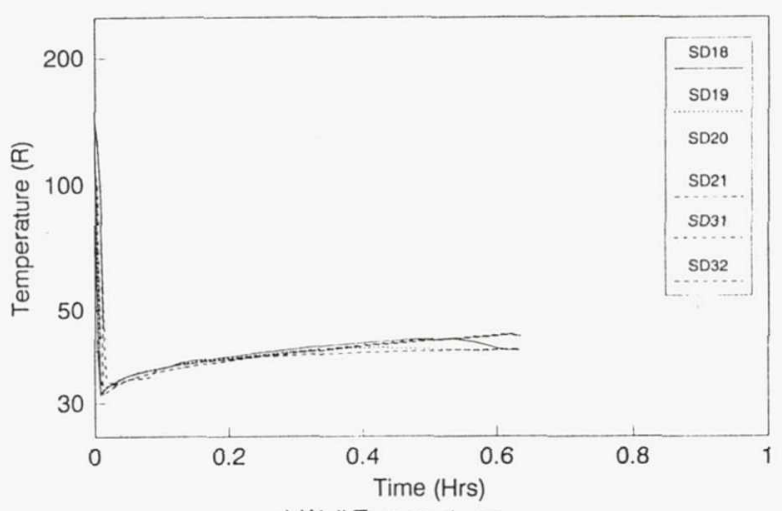

a) Wall Temperatures

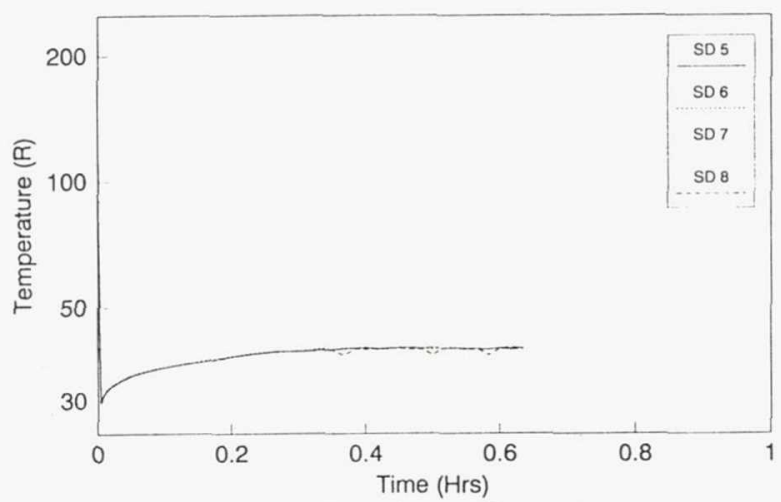

c) Close Range Upper Internal Temperatures

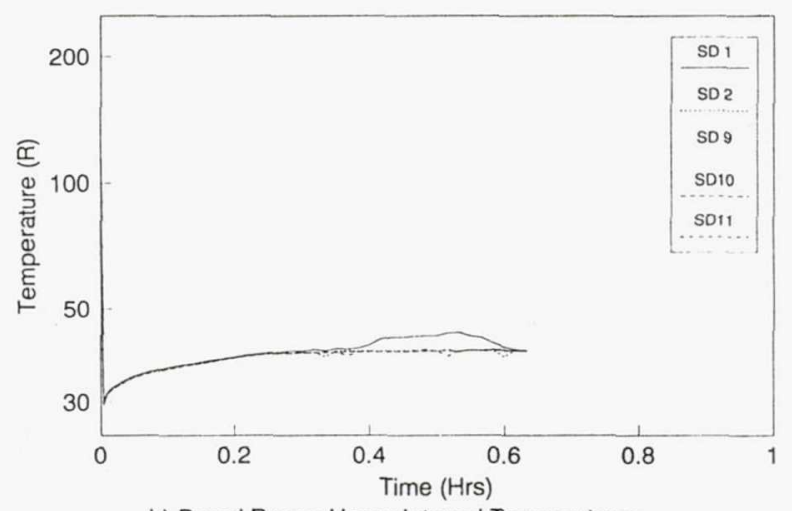

b) Broad Range Upper Internal Temperatures

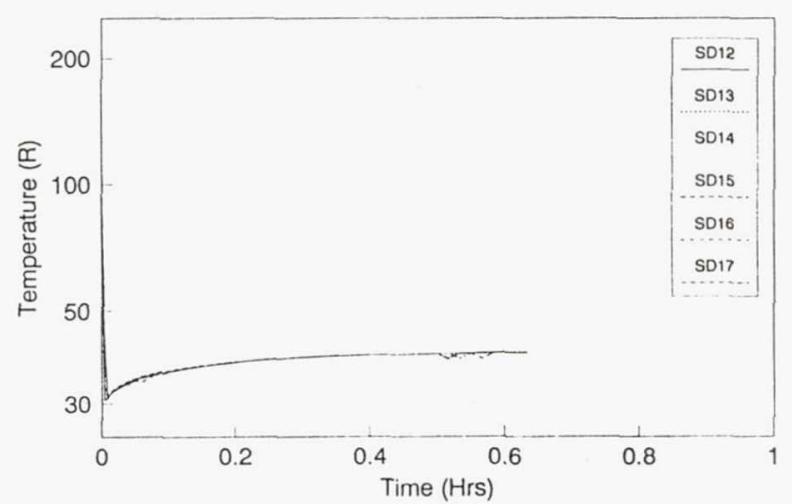

d) Lower Internal Temperatures

Figure 23.-Temperatures for test 22.

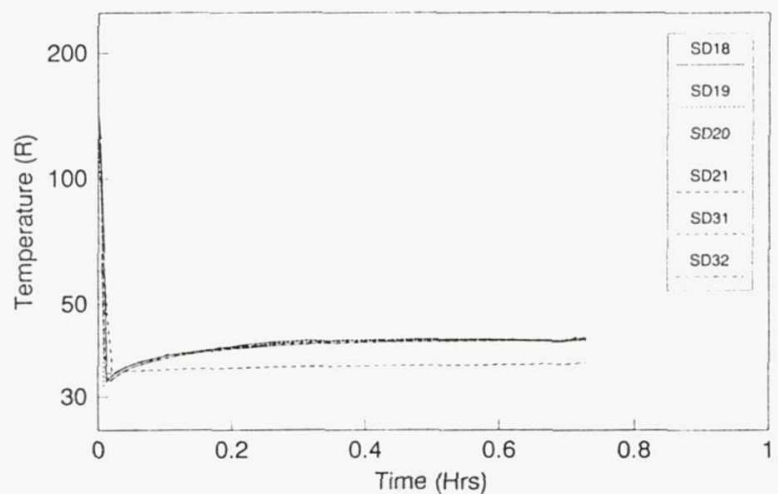

a) Wall Temperatures

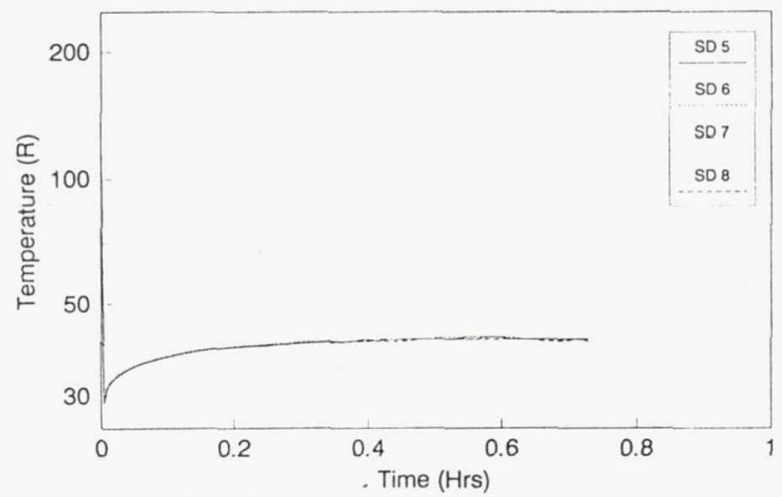

c) Close Range Upper Internal Temperatures

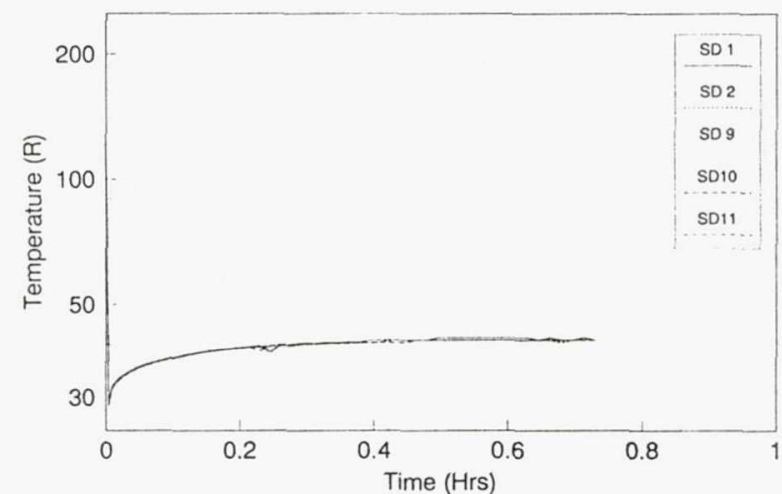

b) Broad Range Upper Internal Temperatures

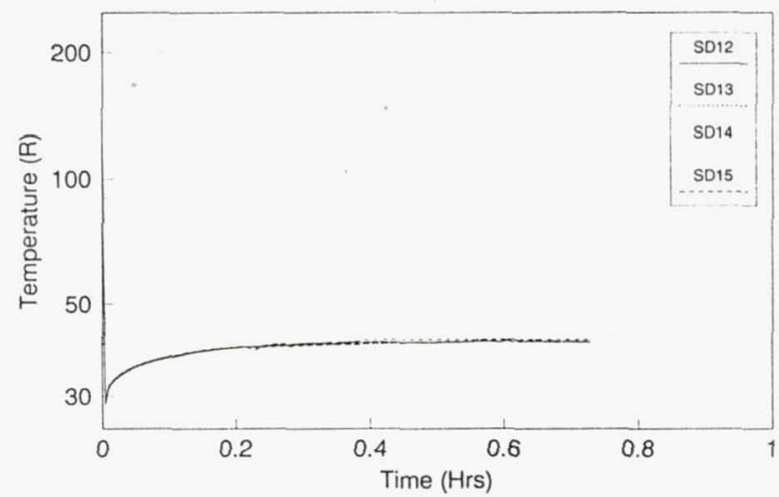

d) Lower Internal Temperatures

Figure 24.-Temperatures for test 23. 


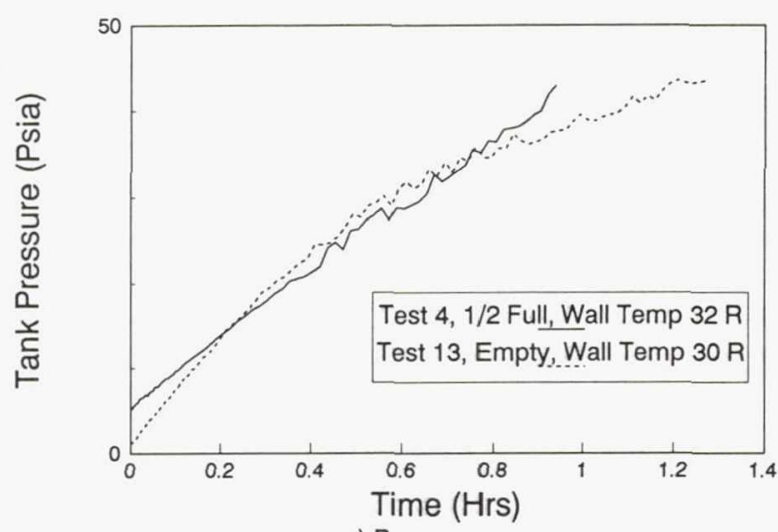

a) Pressure

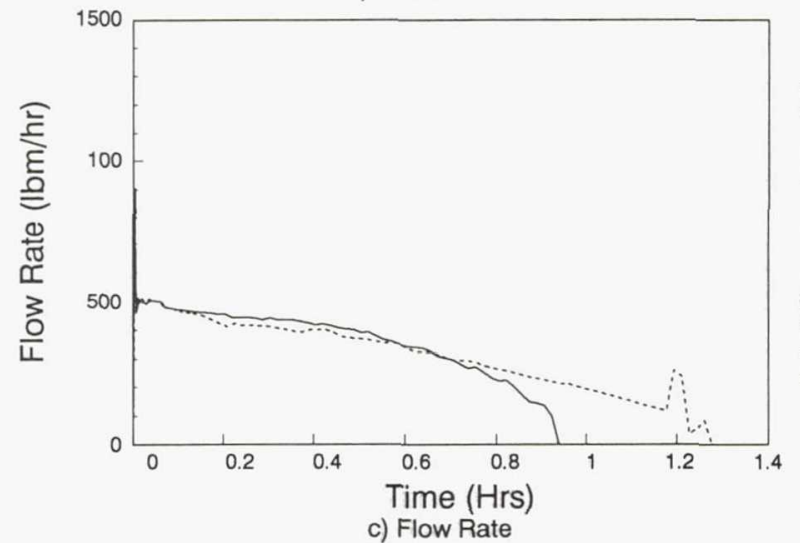

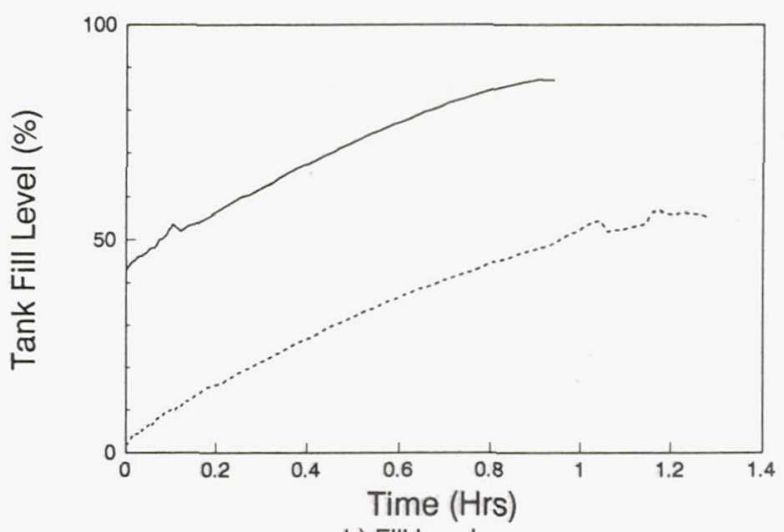

b) Fill Level

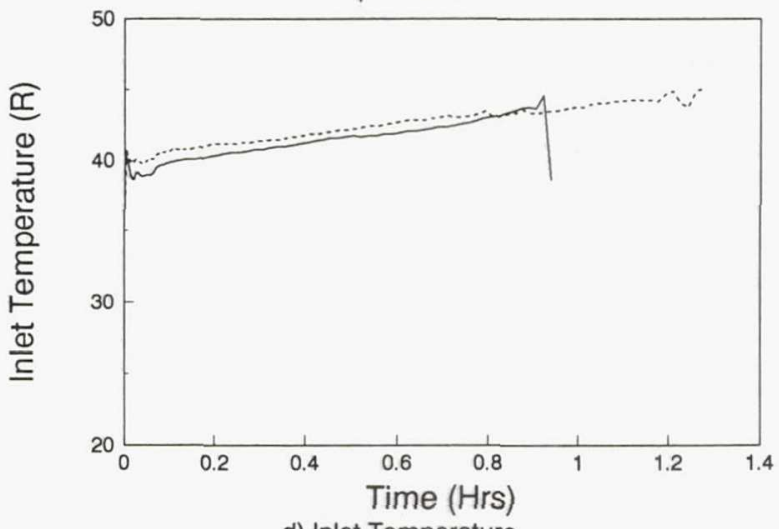

d) Inlet Temperature

Figure 25.-Pressure and inlet conditions for partial fill top spray tests.
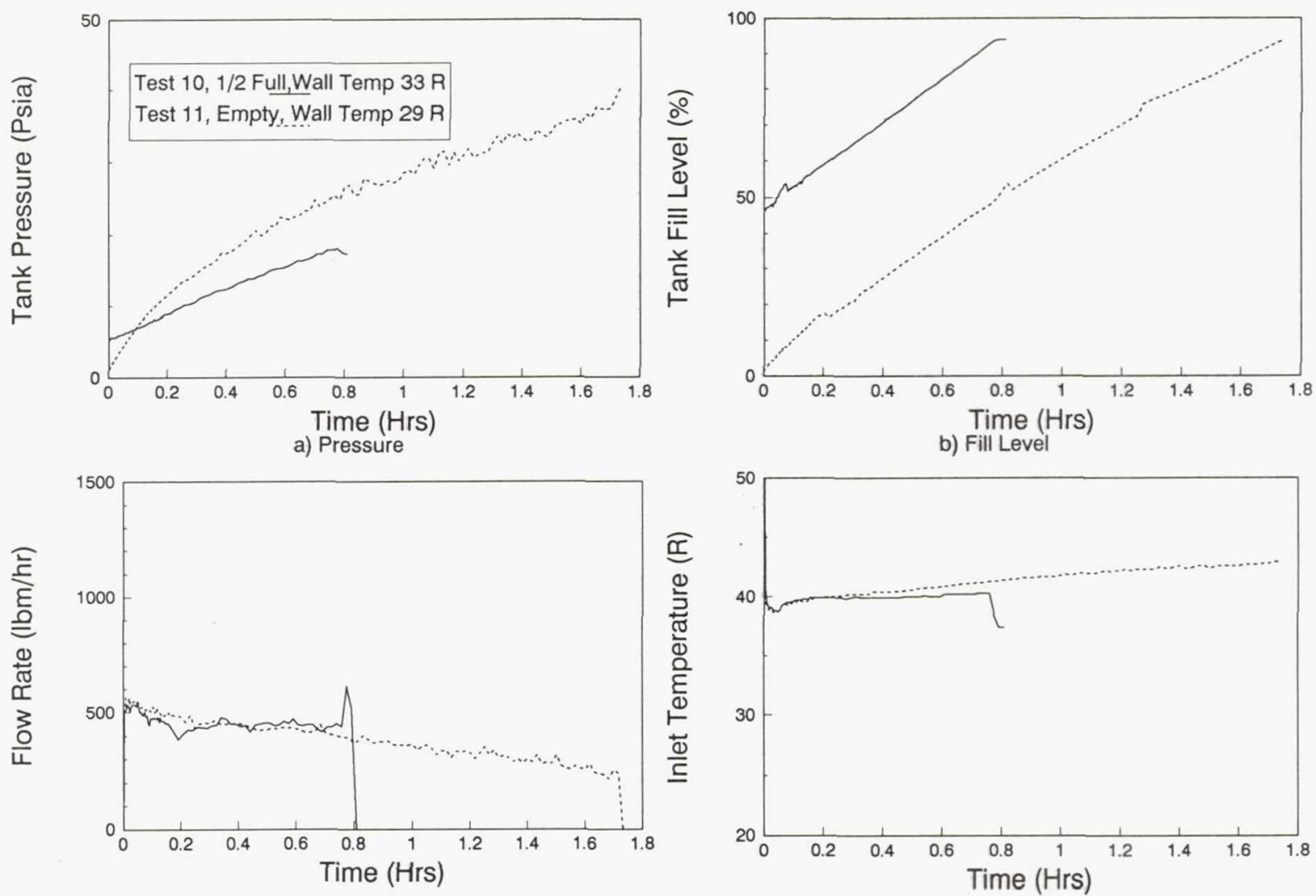

c) Flow Rate

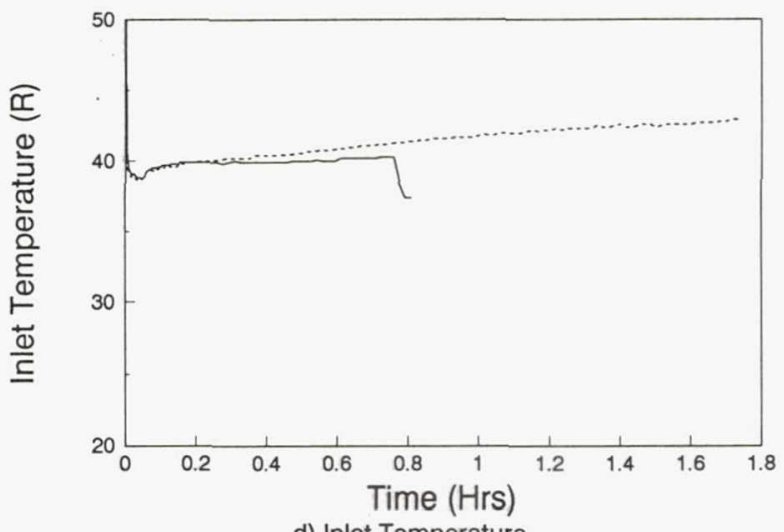

Figure 26.-Pressure and inlet conditions for partial fill bottom spray tests. 


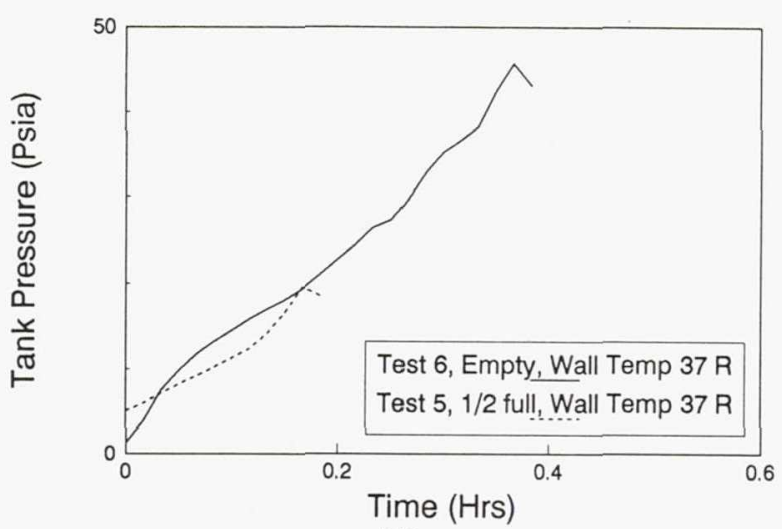

a) Pressure

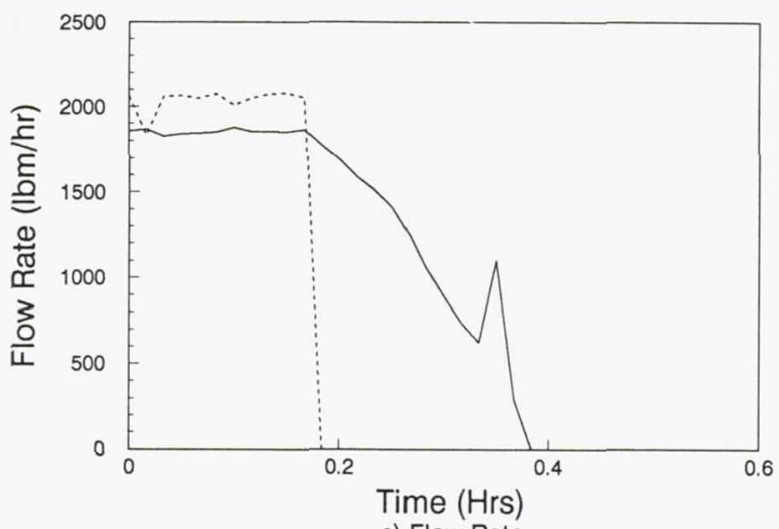

c) Flow Rate

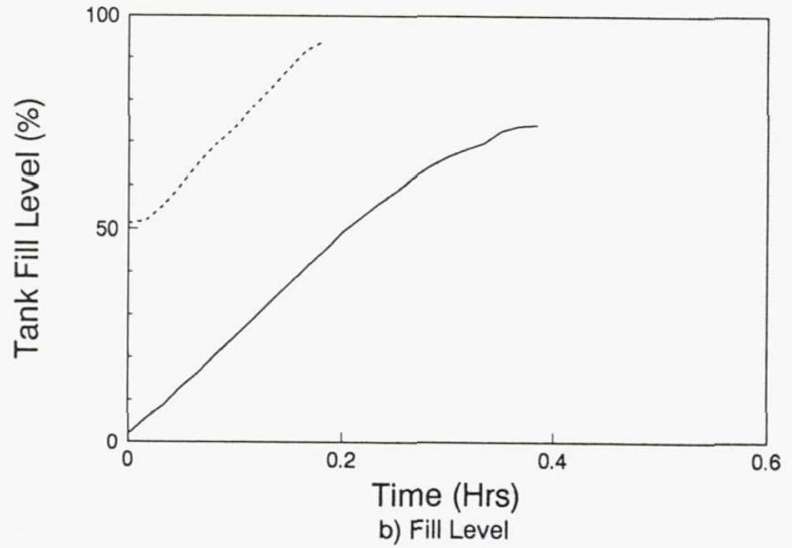

b) Fill Level

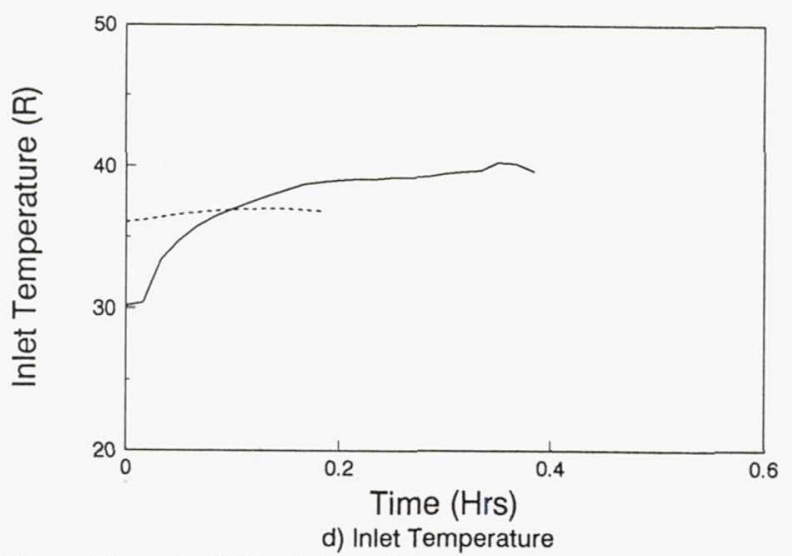

Figure 27.-Pressure and inlet conditions for fill/drain line fill tests.

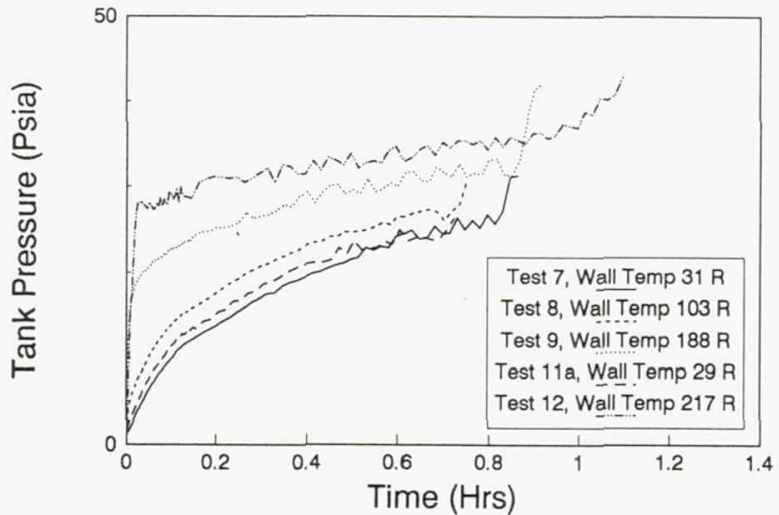

a) Pressure

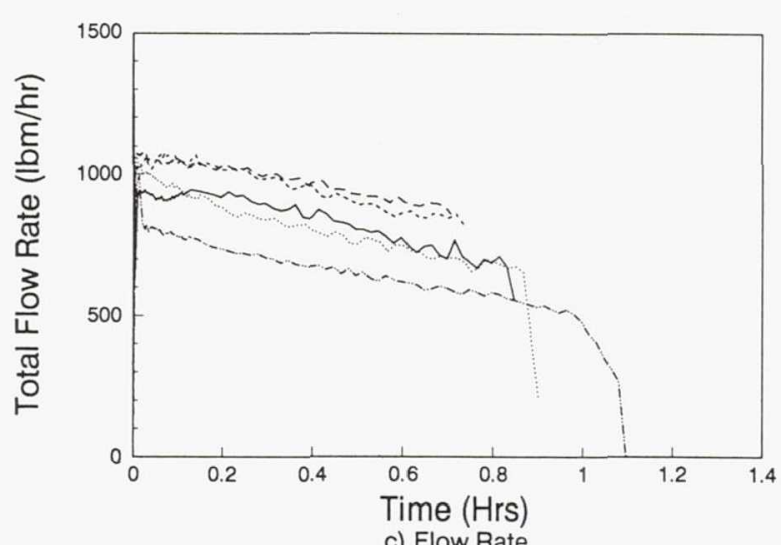

c) Flow Rate

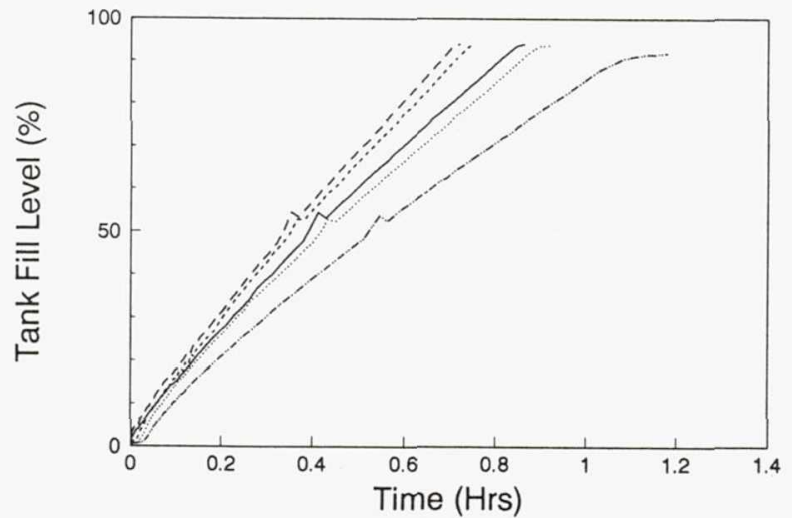

b) Fill Level

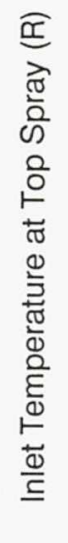

Figure 28.-Pressure and inlet conditions for combined spray fill tests. 

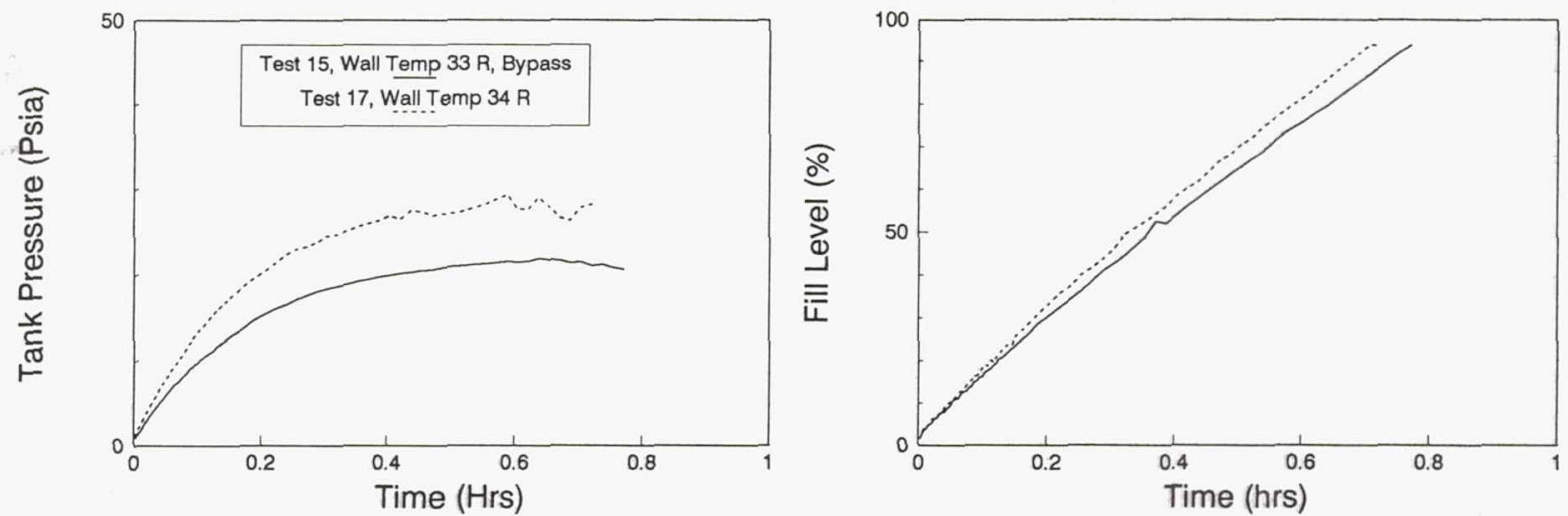

a) Pressure

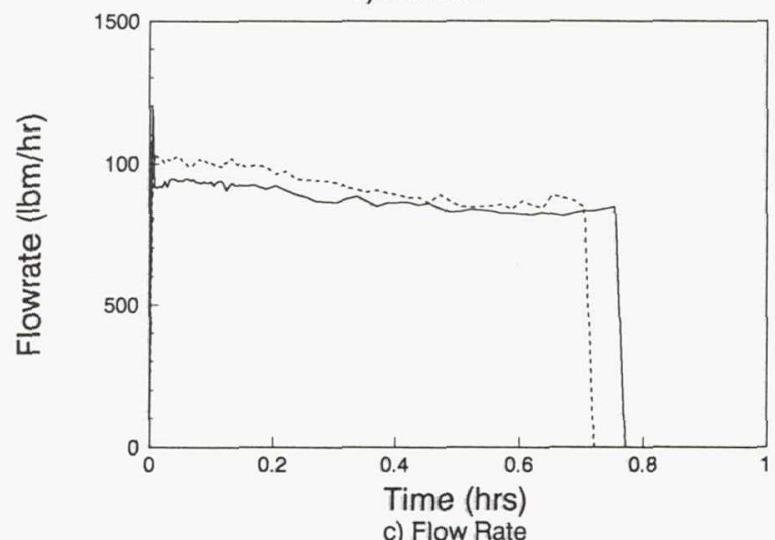

b) Fill Level

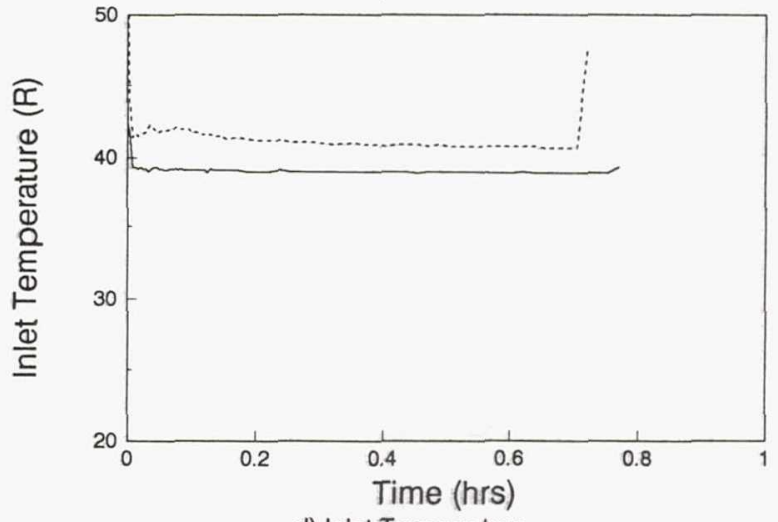

Figure 29.-Pressure and inlet conditions for bypass cooled top spray tests.

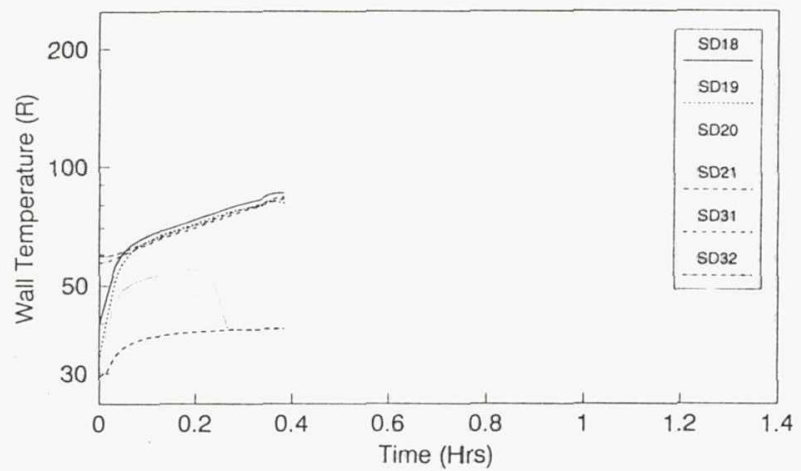

a) Wall Temperature

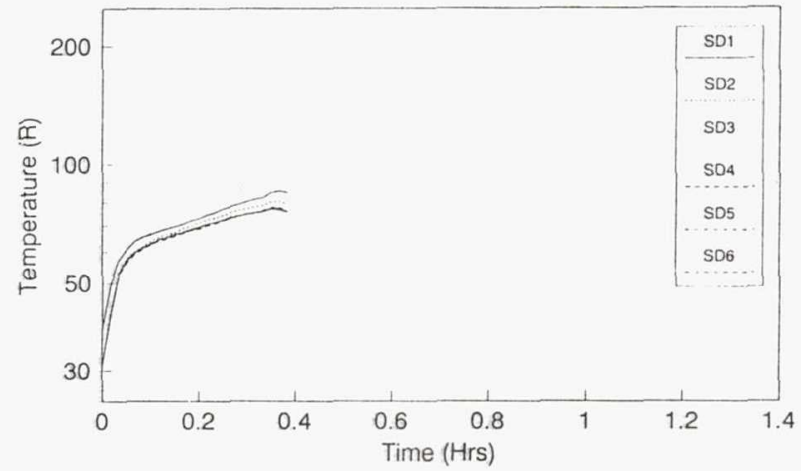

b) Upper Internal Temperatures

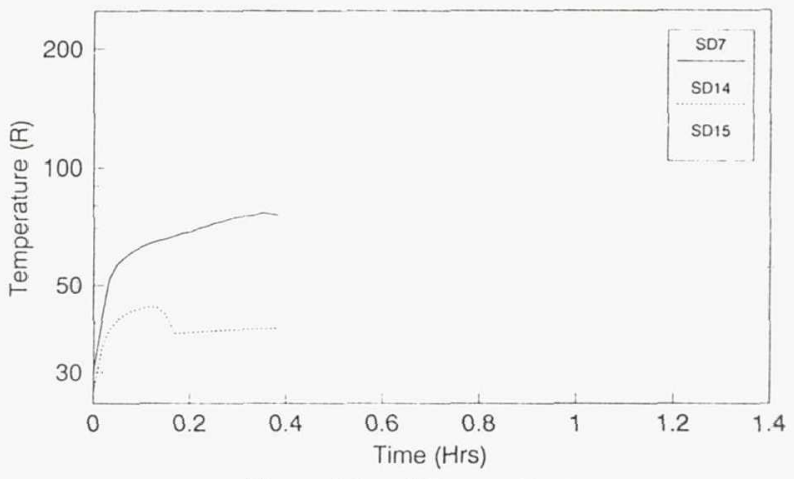

c) Lower Internal Temperatures

Figure 30.-Temperatures for test 6 . 


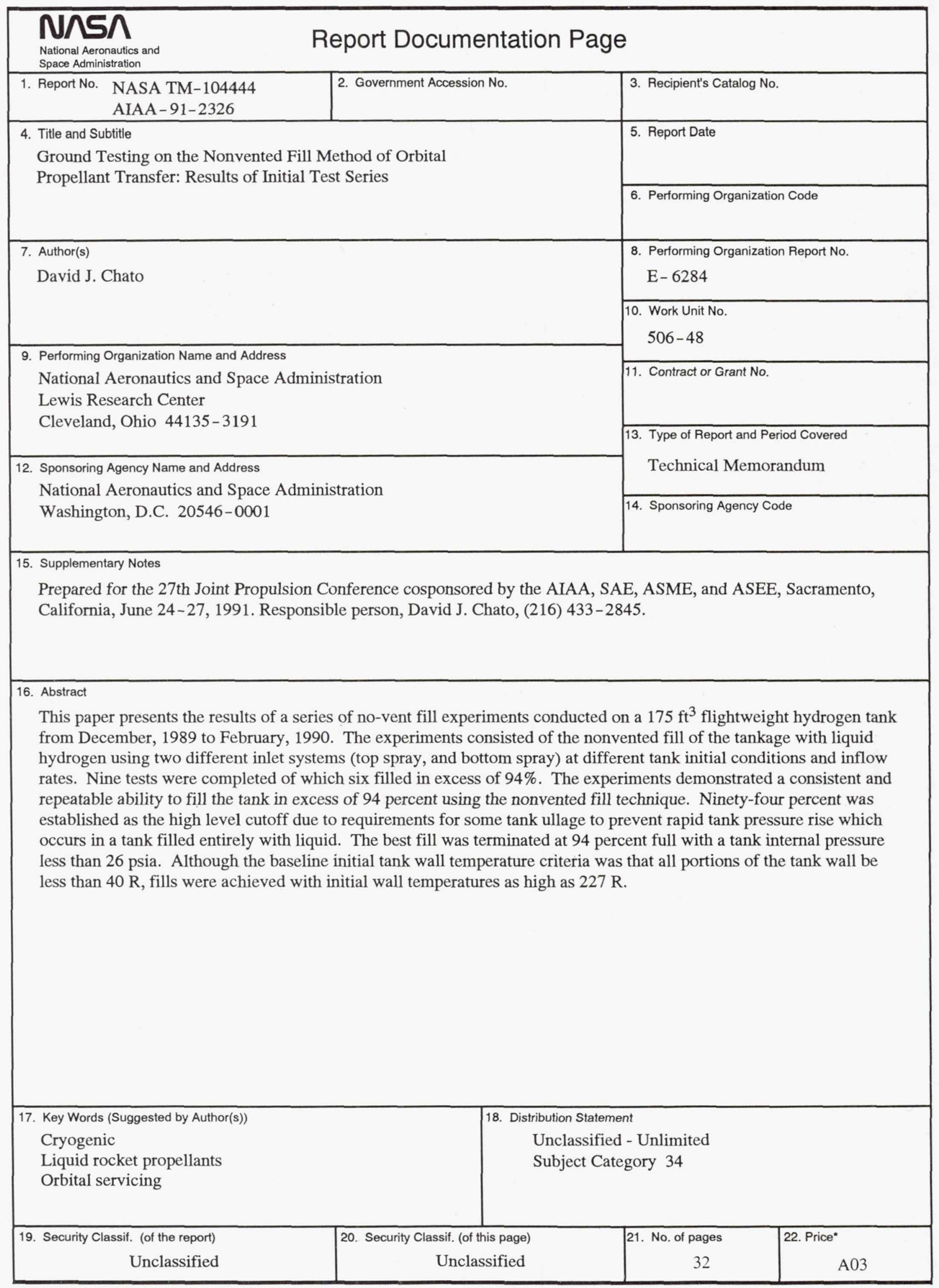

